Article

\title{
Prediction of Chronic Atrophic Gastritis and Gastric Neoplasms by Serum Pepsinogen Assay: A Systematic Review and Meta-Analysis of Diagnostic Test Accuracy
}

\author{
Chang Seok Bang 1,2,3,*(D) Jae Jun Lee ${ }^{2,4}$ and Gwang Ho Baik ${ }^{1,3}$ \\ 1 Department of Internal Medicine, Hallym University College of Medicine, Sakju-ro 77, Chuncheon, \\ Gangwon-do 24253, Korea; baikgh@hallym.or.kr \\ 2 Institute of New Frontier Research, Hallym University College of Medicine, Chuncheon 24253, Korea; \\ iloveu59@hallym.or.kr \\ 3 Institute for Liver and Digestive Diseases, Hallym University, Chuncheon 24253, Korea \\ 4 Department of Anesthesiology and Pain Medicine, Hallym University College of Medicine, \\ Chuncheon 24253, Korea \\ * Correspondence: csbang@hallym.ac.kr; Tel.: +82-33-240-5821; Fax: +82-33-241-8064
}

Received: 4 May 2019; Accepted: 8 May 2019; Published: 10 May 2019

\begin{abstract}
Serum pepsinogen assay (sPGA), which reveals serum pepsinogen (PG) I concentration and the PG I/PG II ratio, is a non-invasive test for predicting chronic atrophic gastritis (CAG) and gastric neoplasms. Although various cut-off values have been suggested, PG I $\leq 70 \mathrm{ng} / \mathrm{mL}$ and a PG I/PG II ratio of $\leq 3$ have been proposed. However, previous meta-analyses reported insufficient systematic reviews and only pooled outcomes, which cannot determine the diagnostic validity of sPGA with a cut-off value of PG I $\leq 70 \mathrm{ng} / \mathrm{mL}$ and/or PG I/PG II ratio $\leq 3$. We searched the core databases (MEDLINE, Cochrane Library, and Embase) from their inception to April 2018. Fourteen and 43 studies were identified and analyzed for the diagnostic performance in CAG and gastric neoplasms, respectively. Values for sensitivity, specificity, diagnostic odds ratio, and area under the curve with a cut-off value of PG I $\leq 70 \mathrm{ng} / \mathrm{mL}$ and PG I/PG II ratio $\leq 3$ to diagnose CAG were 0.59 , $0.89,12$, and 0.81 , respectively and for diagnosis of gastric cancer (GC) these values were $0.59,0.73,4$, and 0.7 , respectively. Methodological quality and ethnicity of enrolled studies were found to be the reason for the heterogeneity in CAG diagnosis. Considering the high specificity, non-invasiveness, and easily interpretable characteristics, sPGA has potential for screening of CAG or GC.
\end{abstract}

Keywords: gastritis; atrophic; pepsinogens; gastric neoplasms

\section{Introduction}

Gastric cancer (GC) is a global health-related burden and the fourth most common cause of cancer-related deaths worldwide [1]. The sequential cascade of histopathology for development of intestinal-type gastric adenocarcinoma is from normal gastric epithelium to chronic gastritis, chronic atrophic gastritis (CAG), and intestinal metaplasia (IM), followed by dysplasia, and finally GC [2]. Patients with premalignant lesions, such as $\mathrm{CAG}$ or dysplasia, have a considerable risk for developing GC, and early detection of these lesions is important for the screening of GC $[3,4]$.

For the population-based screening of GC, the endoscopic mass screening program has shown its efficacy in GC-prevalent countries such as Korea and Japan [5]. The endoscopic screening program reduced GC-related mortality by $47 \%$ in a nested case-control study in Korea [6]. However, it is not cost-effective in regions with low incidence of GC, and stepwise or individualized screening according to the risk factors of GC has been recommended $[4,5]$. 
In addition to endoscopic diagnosis using visual inspection (with or without image-enhanced endoscopy) or histologic diagnosis using an updated Sydney system for CAG or IM, serum pepsinogen assay (sPGA), which reveals concentration of pepsinogen I (PG I) and ratio of PG I/PG II, has been proposed as a non-invasive test for predicting CAG or GC, reflecting gastric mucosal secretory status $[4,7]$.

Although various cut-off values have been suggested, the combination of PG I $\leq 70 \mathrm{ng} / \mathrm{mL}$ and PG I/PG II ratio $\leq 3$ have been proposed for the prediction of CAG or GC $[4,8]$. However, previous meta-analyses for diagnostic test accuracy (DTA) presented only pooled outcomes, which cannot determine the diagnostic validity of sPGA with a cut-off value of PG I $\leq 70 \mathrm{ng} / \mathrm{mL}$ and PG I/PG II ratio $\leq 3[9,10]$, although no threshold effect was detected [9]. This can lead to an exaggerated summary of performance because pooled analysis adopted the best performance value in each study, irrespective of cut-off values. Moreover, several articles were omitted during article searching process, and inaccurate calculation of crude values of diagnostic performance, such as true positive (TP), false positive (FP), true negative (TN), and false negative (FN) values, was detected (Table 1).

Another meta-analysis showed higher discriminative efficacy of combining sPGA with Helicobacter pylori antibody compared to sPGA or H. pylori antibody alone for the prediction of gastric cancer [11]. However, this study presented only comparative efficacy and could not determine the diagnostic validity of each test. Two recently published meta-analyses of DTA showed combined test accuracy of sPGA with $H$. pylori antibody and gastrin-17 for the prediction of CAG (GastroPanel $\left.{ }^{\circledR}\right)[12,13]$. However, this test is not widely available in Asian countries and also the diagnostic validity of sPGA alone was impossible to determine. Although two earlier meta-analyses presented pooled performance of sPGA with cut-off value of PG I $\leq 70 \mathrm{ng} / \mathrm{mL}$ and PG I/PG II ratio $\leq 3[8,14]$, crude values of diagnostic performance used in these studies are unknown. Moreover, diagnostic values with different cut-off standards were coded as those with PG I $\leq 70 \mathrm{ng} / \mathrm{mL}$ and PG I/PG II ratio $\leq 3$, assuming an intrinsic cut-off effect (Table 1).

Therefore, our study aims to provide evidence of sPGA with cut-off value of PG I $\leq 70 \mathrm{ng} / \mathrm{mL}$ and/or PG I/PG II ratio $\leq 3$ for predicting CAG and gastric neoplasms.

\section{Materials and Methods}

This systematic review and meta-analysis fully adhered to the principles of the Preferred Reporting Items for Systematic reviews and Meta-Analyses for Protocols (PRISMA-P) [15]. The protocol of this study was registered at PROSPERO on December 2018 (registration number, CRD42018116470) before the study was initiated. The approval of institutional review board was exempted as the study collected and synthesized data from published literatures [4].

\subsection{Literature Searching Strategy}

MEDLINE (through PubMed), the Cochrane library, and Embase were searched using common keywords associated with sPGA, CAG, and gastric neoplasms, from the time of inception of these databases to March 2019, by two independent evaluators (C.S.B., and J.J.L). Keywords from Medical Subject Heading and Emtree were selected for searching the electronic databases. Abstracts of all the identified studies were reviewed to exclude irrelevant publications. Full-text reviews were performed to determine whether the inclusion criteria were satisfied throughout all the studies. Bibliographies of relevant articles were rigorously reviewed to identify additional studies. Disagreements between the evaluators were resolved by discussion or consultation with a third evaluator (G.H.B.). The detailed searching strategy is described in Table 2 [4]. 
Table 1. Comparison of previous meta-analyses with current study.

\begin{tabular}{|c|c|c|c|c|c|c|c|c|}
\hline Parameters & Current Study & $\begin{array}{l}\text { Dinis-Ribeiro et al. } \\
\text { (2004) [8] }\end{array}$ & Miki et al. (2006) [14] & $\begin{array}{l}\text { Terasawa et al. } \\
\text { (2014) [11] }\end{array}$ & Huang et al. (2015) [9] & $\begin{array}{l}\text { Syrjänen et al. } \\
\text { (2016) [13] }\end{array}$ & $\begin{array}{l}\text { Zagari et al. } \\
\text { (2017) [12] }\end{array}$ & Liu et al. (2019) [10] \\
\hline $\begin{array}{l}\text { Number of } \\
\text { included studies }\end{array}$ & $\begin{array}{l}9 \text { studies for the } \\
\text { diagnosis of CAG and } \\
17 \text { studies for the } \\
\text { diagnosis of GC }\end{array}$ & $\begin{array}{l}25 \text { studies or book } \\
\text { chapters for the diagnosis } \\
\text { of GC }\end{array}$ & $\begin{array}{l}42 \text { studies for the } \\
\text { diagnosis of GC }\end{array}$ & $\begin{array}{l}12 \text { studies for the } \\
\text { diagnosis of GC }\end{array}$ & $\begin{array}{l}16 \text { studies for the } \\
\text { diagnosis of CAG and } \\
15 \text { studies for the } \\
\text { diagnosis of } \mathrm{GC}\end{array}$ & $\begin{array}{l}27 \text { studies for the } \\
\text { diagnosis of CAG }\end{array}$ & $\begin{array}{l}20 \text { studies for the } \\
\text { diagnosis of CAG }\end{array}$ & $\begin{array}{l}19 \text { studies for the } \\
\text { diagnosis of GC }\end{array}$ \\
\hline Main outcome & $\begin{array}{l}\text { Diagnostic validity of } \\
\text { sPGA }\end{array}$ & $\begin{array}{l}\text { Diagnostic validity of } \\
\text { sPGA }\end{array}$ & $\begin{array}{l}\text { Diagnostic validity of } \\
\text { sPGA }\end{array}$ & $\begin{array}{l}\text { Diagnostic validity of } \\
\text { sPGA with Helicobacter } \\
\text { pylori seropositivity }\end{array}$ & $\begin{array}{l}\text { Diagnostic validity of } \\
\text { sPGA }\end{array}$ & $\begin{array}{l}\text { Diagnostic validity of } \\
\text { GastroPanel } \\
\text { (pepsinogen, } \\
\text { gastrin-17, anti } \\
\text { H. pylori antibodies) } \\
\end{array}$ & $\begin{array}{l}\text { Diagnostic validity of } \\
\text { GastroPanel }\end{array}$ & \\
\hline Searching strategy & $\begin{array}{l}\text { PubMed, Embase, } \\
\text { and the Cochrane } \\
\text { Library (only studies } \\
\text { in English) }\end{array}$ & $\begin{array}{l}\text { PubMed and data reports } \\
\text { from Japan (there was no } \\
\text { information about } \\
\text { searching keywords, the } \\
\text { date of searching, the } \\
\text { number of authors who } \\
\text { performed searching, or } \\
\text { how they managed } \\
\text { disagreement or } \\
\text { discrepancy of searching } \\
\text { between authors) }\end{array}$ & $\begin{array}{l}\text { PubMed and data reports } \\
\text { from Japan (there was no } \\
\text { information about } \\
\text { searching keywords, the } \\
\text { date of searching, the } \\
\text { number of authors who } \\
\text { performed searching, or } \\
\text { how they managed } \\
\text { disagreement or } \\
\text { discrepancy of searching } \\
\text { between authors) }\end{array}$ & $\begin{array}{l}\text { PubMed, Web of Science, } \\
\text { the Cochrane Library, } \\
\text { and Japanese Medical } \\
\text { Research Database (only } \\
\text { studies in English or } \\
\text { Japanese). The search } \\
\text { was updated through } \\
\text { citation-tracking }\end{array}$ & $\begin{array}{l}\text { PubMed, Embase, and } \\
\text { the CNKI (only studies } \\
\text { in English or Chinese). } \\
\text { Several articles } \\
\text { were omitted. }\end{array}$ & $\begin{array}{l}\text { MEDLINE } \\
\text { (no language } \\
\text { limitation) }\end{array}$ & $\begin{array}{l}\text { PubMed, Embase, } \\
\text { Scopus, and the } \\
\text { Cochrane Library }\end{array}$ & $\begin{array}{l}\text { PubMed, Embase, } \\
\text { the Cochrane Library, } \\
\text { CNKI, WanFang, VIP, } \\
\text { and CBM databases } \\
\text { (only studies in } \\
\text { English or Chinese). } \\
\text { Several articles } \\
\text { were omitted. }\end{array}$ \\
\hline Cut-off value & $\begin{array}{l}\mathrm{PG} \mathrm{I} \leq 70 \mathrm{ng} / \mathrm{mL} \\
\text { and/or PG I/II } \leq 3\end{array}$ & $\begin{array}{l}\mathrm{PG} \mathrm{I} \leq 70 \mathrm{ng} / \mathrm{mL} \text { and PG } \\
\mathrm{I} / \mathrm{II} \text { ratio } \leq 3, \mathrm{PG} \mathrm{I} \leq 50 \\
\mathrm{ng} / \mathrm{mL} \text { and } \mathrm{PG} \mathrm{I} / \mathrm{II} \text { ratio } \\
\leq 3, \mathrm{PG} \mathrm{I} \leq 30 \mathrm{ng} / \mathrm{mL} \text { and } \\
\text { PG I/II ratio } \leq 2\end{array}$ & $\begin{array}{l}\mathrm{PG} \mathrm{I} \leq 70 \mathrm{ng} / \mathrm{mL} \text { and } \mathrm{PG} \\
\mathrm{I} / \mathrm{II} \text { ratio } \leq 3\end{array}$ & $\begin{array}{l}\mathrm{PG} \mathrm{I} \leq 70 \mathrm{ng} / \mathrm{mL} \text { and } \\
\text { PG I/II ratio } \leq 3\end{array}$ & $\begin{array}{l}\text { Diagnostic values with } \\
\text { various cut-off } \\
\text { standards were pooled } \\
\text { in a single outcome }\end{array}$ & & & $\begin{array}{l}\text { Diagnostic values } \\
\text { with various cut-off } \\
\text { standards were } \\
\text { pooled in a single } \\
\text { outcome }\end{array}$ \\
\hline $\begin{array}{l}\text { Inaccurate } \\
\text { calculation } \\
\text { (coding) of } \\
\text { TP/FP/FN/TN }\end{array}$ & & $\begin{array}{l}\text { Unknown (crude value of } \\
\text { TP/FP/FN/TN in each } \\
\text { study is not described) }\end{array}$ & $\begin{array}{l}\text { Unknown (crude value of } \\
\mathrm{TP} / \mathrm{FP} / \mathrm{FN} / \mathrm{TN} \text { in each } \\
\text { study is not described). } \\
\text { Many studies with } \\
\text { different cut-off values } \\
\text { were coded as those of PG } \\
\mathrm{I} \leq 70 \mathrm{ng} / \mathrm{mL} \text { and PG I/II } \\
\text { ratio } \leq 3 \text { (intrinsic cutoff } \\
\text { effect was assumed) }\end{array}$ & $\begin{array}{l}\text { Not a meta-analysis with } \\
\text { DTA. Hazard ratio was } \\
\text { the effect size and } \\
\text { conventional } \\
\text { meta-analysis was done. }\end{array}$ & $\begin{array}{l}\text { Detected in } \\
\text { several studies }\end{array}$ & $\begin{array}{l}\text { Unknown. Not a } \\
\text { meta-analysis with } \\
\text { diagnostic test } \\
\text { accuracy (DTA). } \\
\text { Sensitivity and } \\
\text { specificity of each } \\
\text { study was pooled } \\
\text { using conventional } \\
\text { meta-analysis method. }\end{array}$ & & $\begin{array}{l}\text { Detected in } \\
\text { several studies }\end{array}$ \\
\hline $\begin{array}{l}\text { Determination of } \\
\text { heterogeneity }\end{array}$ & $\begin{array}{l}\text { Correlation } \\
\text { coefficient between } \\
\text { the logarithm of the } \\
\text { sensitivity and } \\
\text { specificity, beta of } \\
\text { HSROC model, visual } \\
\text { examination of the } \\
\text { SROC curve }\end{array}$ & $\begin{array}{l}\text { Chi-squared test } \\
\text { (Cochrane Q statistic) } \\
\text { with subgroup analysis } \\
\text { according to the study } \\
\text { population; } \\
\text { (population-based study } \\
\text { vs. GC screening in } \\
\text { selected groups) }\end{array}$ & $\begin{array}{l}\text { Chi-squared test } \\
\text { (Cochrane Q statistic) } \\
\text { (whether meta-regression } \\
\text { was done or not } \\
\text { is unknown) }\end{array}$ & $I^{2}$ statistics & $\begin{array}{l}I^{2} \text { statistics, correlation } \\
\text { coefficient between } \\
\text { sensitivity. Whether } \\
\text { the correlation } \\
\text { coefficient is between } \\
\text { sensitivity and false } \\
\text { positive rate or } \\
\text { between sensitivity } \\
\text { and specificity is not } \\
\text { clearly defined. }\end{array}$ & $I^{2}$ statistics & $\begin{array}{l}\text { Visual } \\
\text { examination of the } \\
\text { forest plot and } \\
\text { SROC curve }\end{array}$ & $\begin{array}{l}I^{2} \text { statistics, Spearman } \\
\text { correlation } \\
\text { coefficient between } \\
\text { the logarithm of the } \\
\text { sensitivity and } \\
\text { the logarithm of the } \\
\text { (1-specificity), visual } \\
\text { examination of the } \\
\text { forest plot and } \\
\text { SROC curve }\end{array}$ \\
\hline
\end{tabular}


Table 1. Cont.

\begin{tabular}{|c|c|c|c|c|c|c|c|c|}
\hline Parameters & Current Study & $\begin{array}{l}\text { Dinis-Ribeiro et al. } \\
\text { (2004) [8] }\end{array}$ & Miki et al. (2006) [14] & $\begin{array}{c}\text { Terasawa et al. } \\
\text { (2014) [11] }\end{array}$ & Huang et al. (2015) [9] & $\begin{array}{l}\text { Syrjänen et al. } \\
\text { (2016) [13] }\end{array}$ & $\begin{array}{c}\text { Zagari et al. } \\
\text { (2017) [12] }\end{array}$ & Liu et al. (2019) [10] \\
\hline $\begin{array}{l}\text { Quality } \\
\text { assessment }\end{array}$ & QUADAS-2 & None & None & QUIPS-2, PROBAST & QUADAS-2 & None & QUADAS-2 & QUADAS \\
\hline $\begin{array}{l}\text { Inaccurate coding } \\
\text { for subgroup } \\
\text { analysis }\end{array}$ & & & & & $\begin{array}{l}\text { Study design was } \\
\text { inaccurately coded in } \\
\text { several studies. }\end{array}$ & & & \\
\hline
\end{tabular}

CAG, chronic atrophic gastritis; GC, gastric cancer; sPGA, serum pepsinogen assay; CNKI, China National Knowledge Infrastructure; VIP, Chongqing VIP Chinese Science and Technology Periodical Database; CBM, Chinese BioMedical Database; PG, pepsinogen; TP, true positive; FP, false positive; FN, false negative; TN, true negative; HSROC, hierarchical summary receiver operating characteristic; SROC, summary receiver operating characteristic; QUADAS, Quality Assessment of Diagnostic Accuracy Studies; QUIPS, Quality In Prognosis Studies; PROBAST, Prediction model Risk of Bias Assessment tool. 
Table 2. Searching strategy to find the relevant articles.

\begin{tabular}{|c|c|}
\hline \multicolumn{2}{|c|}{$<$ For CAG> } \\
\hline \multicolumn{2}{|c|}{ Database: MEDLINE (through PubMed) } \\
\hline & "gastric atrophy"[tiab] OR "atrophic gastritis"[Mesh] \\
\hline & "precancerous lesion" [tiab] OR "precancerous conditions"[Mesh] \\
\hline$\# 3$ & \#1 OR \#2 \\
\hline \#4 & $\begin{array}{l}\text { "pepsinogen I"[tiab] OR "pepsinogen II"[tiab] OR "pepsinogen I/II"[tiab] OR "pepsinogens" [Mesh] OR } \\
\text { "pepsinogen A"[tiab] OR "pepsinogen C"[tiab] }\end{array}$ \\
\hline \#5 & \#3 AND \#4 \\
\hline \#6 & \#5 English[Lang] \\
\hline \multicolumn{2}{|c|}{ Database: Embase } \\
\hline & 'gastric atrophy':ab,ti,kw OR 'atrophic gastritis':ab,ti,kw OR 'atrophic gastritis'/exp \\
\hline & 'precancerous lesion':ab,ti,kw OR 'precancerous condition':ab,ti,kw \\
\hline \#3 & \#1 OR \#2 \\
\hline$\# 4$ & $\begin{array}{l}\text { 'pepsinogen':ab,ti,kw OR 'pepsinogen I'/exp OR 'pepsinogen II'/exp OR 'pepsinogen I/II':ab,ti,kw OR } \\
\text { 'pepsinogen A'/exp OR 'pepsinogen C'/exp }\end{array}$ \\
\hline \#5 & \#3 AND \#4 \\
\hline \#6 & \#5 AND ([article]/lim OR [article in press]/lim OR [review]/lim) AND [english]/lim \\
\hline \multicolumn{2}{|c|}{ Database: Cochrane Library } \\
\hline$\# 1$ & gastric atrophy:ab,ti,kw \\
\hline \#2 & MeSH descriptor: [atrophic gastritis] explode all trees \\
\hline \#3 & precancerous lesion:ab,ti,kw \\
\hline$\# 4$ & MeSH descriptor: [precancerous conditions] explode all trees \\
\hline \#5 & $\# 1$ or \#2 or \#3 or \#4 \\
\hline \#6 & pepsinogen I:ab,ti,kw or pepsinogen II:ab,ti,kw or pepsinogen A:ab,ti,kw or pepsinogen C:ab,ti,kw \\
\hline \#7 & MeSH descriptor: [pepsinogens] explode all trees \\
\hline$\# 8$ & \#6 or \#7 \\
\hline \#9 & $\# 5$ and \#8 \\
\hline \multicolumn{2}{|c|}{$<$ For gastric neoplasm> } \\
\hline \multicolumn{2}{|c|}{ Database: MEDLINE (through PubMed) } \\
\hline & $\begin{array}{l}\text { "gastric cancer"[tiab] OR "gastric neoplasm"[tiab] OR "stomach cancer"[tiab] OR "stomach } \\
\text { neoplasm"[tiab] OR “dysplasia"[tiab] OR “stomach neoplasms"[Mesh] }\end{array}$ \\
\hline \#2 & $\begin{array}{l}\text { "pepsinogen I"[tiab] OR "pepsinogen II"[tiab] OR "pepsinogen I/II"[tiab] OR "pepsinogens" [Mesh] OR } \\
\text { "pepsinogen A"[tiab] OR "pepsinogen C"[tiab] }\end{array}$ \\
\hline \#3 & $\# 1 \mathrm{AND} \# 2$ \\
\hline & \#3 English[Lang] \\
\hline \multicolumn{2}{|c|}{ Database: Embase } \\
\hline$\# 1$ & $\begin{array}{l}\text { 'gastric cancer':ab,ti,kw OR 'gastric neoplasm':ab,ti,kw OR 'dysplasia':ab,ti,kw OR 'stomach cancer'/exp } \\
\text { OR ‘stomach tumor'/exp }\end{array}$ \\
\hline$\# 2$ & $\begin{array}{l}\text { “pepsinogen':ab,ti,kw OR 'pepsinogen I'/exp OR 'pepsinogen II'/exp OR 'pepsinogen I/II':ab,ti,kw OR } \\
\text { 'pepsinogen A'/exp OR 'pepsinogen C'/exp }\end{array}$ \\
\hline \#3 & \#1 AND \#2 \\
\hline & \#3 AND ([article]/lim OR [article in press]/lim OR [review]/lim) AND [english]/lim \\
\hline
\end{tabular}


Table 2. Cont.

\begin{tabular}{ll}
\hline <For gastric neoplasm> \\
\hline Database: Cochrane Library \\
\hline$\# 1 \quad \begin{array}{l}\text { gastric cancer:ab,ti,kw or gastric neoplasm:ab,ti,kw or stomach cancer:ab,ti,kw or stomach } \\
\text { neoplasm:ab,ti,kw or dysplasia:ab,ti,kw }\end{array}$ \\
\hline$\# 2 \quad$ MeSH descriptor: [stomach neoplasms] explode all trees \\
\hline$\# 3 \quad \# 1$ or \#2 \\
\hline$\# 4 \quad$ pepsinogen I:ab,ti,kw or pepsinogen II:ab,ti,kw or pepsinogen A:ab,ti,kw or pepsinogen C:ab,ti,kw \\
\hline$\# 5 \quad$ MeSH descriptor: [pepsinogens] explode all trees \\
\hline$\# 6 \quad \# 4$ or \#5 \\
\hline$\# 7 \quad \# 3$ and \#6 \\
\hline
\end{tabular}

CAG, chronic atrophic gastritis.

\subsection{Selection Criteria}

We included studies that met the following criteria. Patients (1) who have CAG or gastric neoplasms (dysplasia or cancer); (2) intervention: sPGA with cut-off value of PG I $\leq 70 \mathrm{ng} / \mathrm{mL}$ and/or PG I/PG II ratio $\leq 3$; (3) comparison: none; (4) outcome: diagnostic performance indices of sPGA for CAG or gastric neoplasms including sensitivity, specificity, positive predictive value (PPV), negative predictive value (NPV), positive likelihood ratio (PLR), negative likelihood ratio (NLR), accuracy, or diagnostic odds ratio (DOR), which enable an estimation of TP, FP, TN, and FN values; (5) study design: all types; (6) studies of human subjects; and (7) full-text publications written in English. Studies that met all of the inclusion criteria were sought and selected. The exclusion criteria were as follows: (1) narrative review; (2) letter, comment, editorial or reply to questions; (3) study protocol; (4) publication with incomplete data; and (5) systematic review/meta-analysis or consensus report. Studies meeting at least one of the exclusion criteria were excluded from this analysis.

\subsection{Methodological Quality}

The methodological quality of the included publications was assessed using the Quality Assessment of Diagnostic Accuracy Studies-2 (QUADAS-2) tool, which contains four domains, including "patient selection", "index test", "reference standard", and "flow and timing" (flow of patients through the study and timing of the index tests and reference standard) [16]. Each domain is assessed in terms of high-, low-, or unclear risk of bias, and the first three domains are also assessed in terms of high-, low-, or unclear concerns about applicability [16]. Two of the evaluators (C.S.B. and J.J.L.) independently assessed the methodological quality of all the included studies, and any disagreements between the evaluators were resolved by discussion or consultation with a third evaluator (G.H.B.) [4].

\subsection{Data Extraction and Primary and Modifier-Based Analyses}

Two evaluators (C.S.B. and J.J.L.) independently used the same data fill-in form to collect the summary of primary outcomes (TP, FP, FN, and TN) and modifiers in each study. Disagreements between the two evaluators were resolved by discussion or consultation with a third author (G.H.B).

DTA was the primary outcome of this study. We calculated the values for TP (subjects with positive sPGA who have CAG or gastric neoplasms), FP (subjects with positive sPGA who do not have CAG or gastric neoplasms), FN (subjects with negative sPGA who have CAG or gastric neoplasms), and TN (subjects with negative sPGA who do not have CAG or gastric neoplasms) of sPGA for the diagnosis of CAG or gastric neoplasm. To calculate the values, we used $2 \times 2$ tables whenever possible, from the original articles that contain various diagnostic performance indices (sensitivity, specificity, PPV, NPV, PLR, NLR, accuracy, or DOR etc.). If only a part of data was presented, we calculated the 
values for TP, FP, FN, and TN using the following formulas: sensitivity $=\mathrm{TP} /(\mathrm{TP}+\mathrm{FN})$; specificity $=$ $\mathrm{TN} /(\mathrm{FP}+\mathrm{TN}) ; \mathrm{PPV}=\mathrm{TP} /(\mathrm{TP}+\mathrm{FP}) ; \mathrm{NPV}=\mathrm{TN} /(\mathrm{FN}+\mathrm{TN}) ; \mathrm{PLR}=$ sensitivity/(1-specificity); NLR = $(1$-sensitivity $) /$ specificity; accuracy $=(\mathrm{TP}+\mathrm{TN}) /(\mathrm{TP}+\mathrm{FP}+\mathrm{FN}+\mathrm{TN}) ; \mathrm{DOR}=(\mathrm{TP} \times \mathrm{TN}) /(\mathrm{FP} \times \mathrm{FN})$; standard error $=(\ln ($ upper confidence interval $(\mathrm{CI}))-\ln ($ lower CI $)) / 3.92=\sqrt{ }(1 / \mathrm{TP}+1 / \mathrm{FP}+1 / \mathrm{FN}+1 / \mathrm{TN})$.

The following data were also extracted from each study, whenever possible: study design, distribution of age, gender or ethnicity of enrolled population, sample size, published year, measurement method of sPGA, and the proportion of smokers and H. pylori-infected individuals.

\subsection{Statistical Analysis}

Stata Statistical Software, version 15.1 (College Station, TX, USA) including relevant packages, such as metandi, midas, and mylabels, was used for this meta-analysis.

Narrative (descriptive) synthesis was planned and quantitative synthesis (bivariate random model [17] and hierarchical summary receiver operating characteristic (HSROC) model [18]) was used if the included studies were sufficiently homogenous. We calculated or extracted TP, FP, FN, and TN values from each study. A Forest plot of pooled sensitivity or specificity using a bivariate model and summary receiver operating characteristic (SROC) curve using a HSROC model were generated. Heterogeneity across the studies was determined by correlation coefficient between logit transformed sensitivity and specificity using bivariate model [17] and asymmetry parameter, $\beta$ (beta), where $\beta=0$ corresponds to a symmetric receiver operating characteristic (ROC) curve in which the DOR does not vary along the curve by HSROC model. A positive correlation coefficient (greater than 0 ) and $\beta$ with significant $p$ value $(p<0.05)$ indicate heterogeneity between studies $[18,19]$. Visual examination of the SROC curve was also performed to find heterogeneity. We also performed meta-regression and subgroup analyses using the modifiers identified during the systematic review to confirm robustness of the main result and to identify the reason of heterogeneity. Publication bias was evaluated using Deeks' funnel plot asymmetry test.

\section{Results}

\subsection{Identification of Relevant Studies}

Figure 1 presents a flow diagram showing the process to identify the relevant studies. For CAG diagnosis, a total of 855 articles were identified by searching four electronic databases and additional hand-searching. Among those articles, 174 were duplicate studies, and 552 additional studies were excluded during the initial screening by reviewing titles and abstracts. Full texts of the remaining 129 studies were then thoroughly reviewed. Among these studies, 115 articles were excluded from the final analysis due to the following reasons: narrative review article $(n=13)$, letter, comment, editorial or reply to questions $(n=1)$, study protocol $(n=1)$, incomplete data $(n=92)$, and systematic review/meta-analysis or consensus report $(n=8)$. The remaining 14 studies [20-33] were included in the quantitative synthesis. Eight studies [20,23,24,27,29-32] adopted the cut-off standard of PG I $\leq 70 \mathrm{ng} / \mathrm{mL}$ and PG I/PG II ratio $\leq 3$, eight studies $[21,22,25-28,30,33]$ adopted the cut-off standard of PG I/PG II ratio $\leq 3$, and only two studies [27,33] adopted the cut-off standard of PG I $\leq 70 \mathrm{ng} / \mathrm{mL}$.

For gastric neoplasm diagnosis, a total of 1408 articles were identified by searching four electronic databases. Among those articles, 538 were duplicate studies, and 685 additional studies were excluded during the initial screening by reviewing titles and abstracts. The full texts of the remaining 185 studies were then thoroughly reviewed. Among these studies, 142 articles were excluded from the final analysis, due to the following reasons: narrative review article $(n=30)$, letter, comment, editorial or reply to questions $(n=6)$, study protocol $(n=6)$, incomplete data $(n=88)$, and systematic review/meta-analysis or consensus report $(n=12)$. The remaining 43 studies [21,26,27,34-73], including 38 studies [26,34-54,56-60,62-66,68-73] evaluating the performance of sPGA for the diagnosis of GC, four studies $[21,27,45,73]$ for the diagnosis of gastric dysplasia, and four studies $[55,61,67,71]$ for the diagnosis of gastric neoplasm, were incorporated in the quantitative synthesis. 


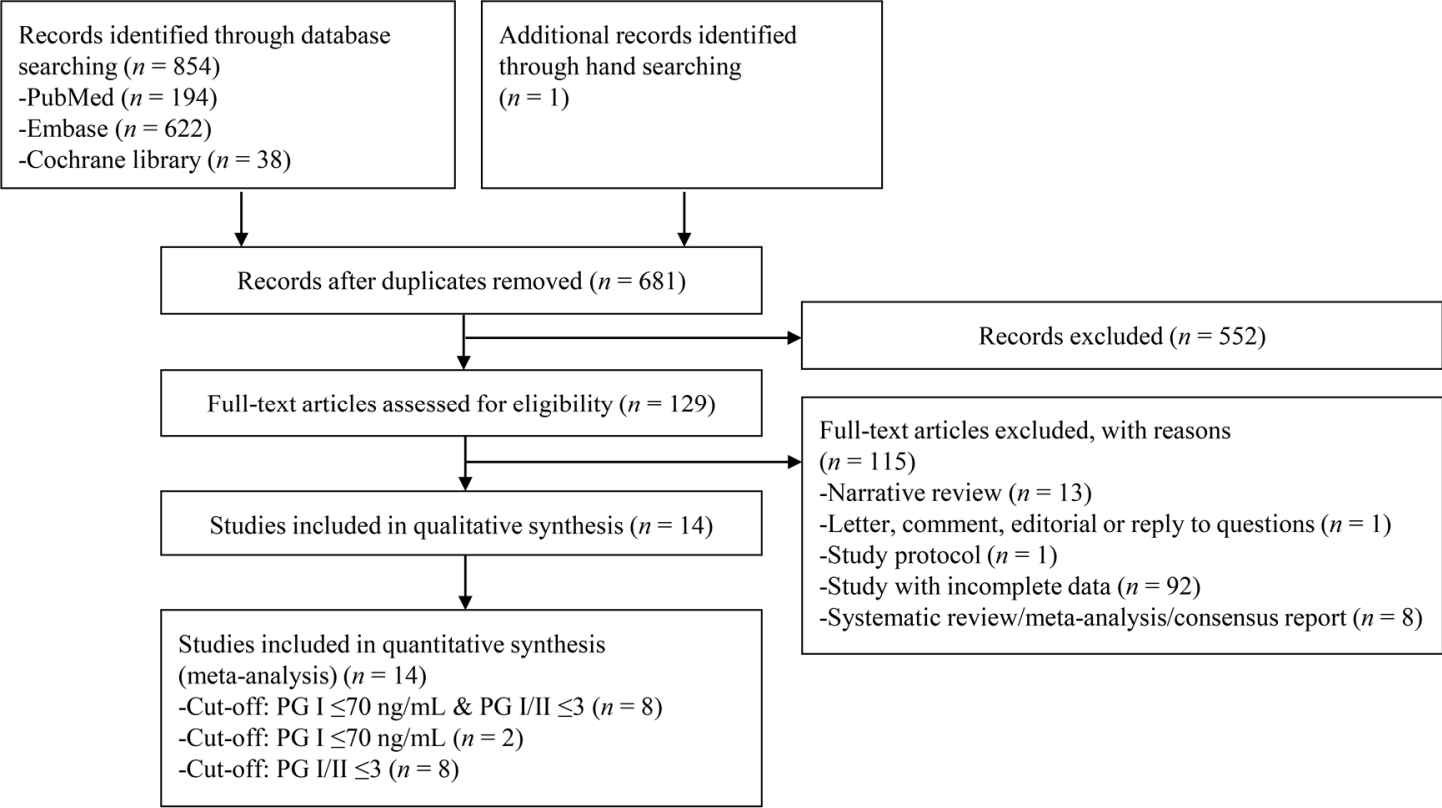

(A)

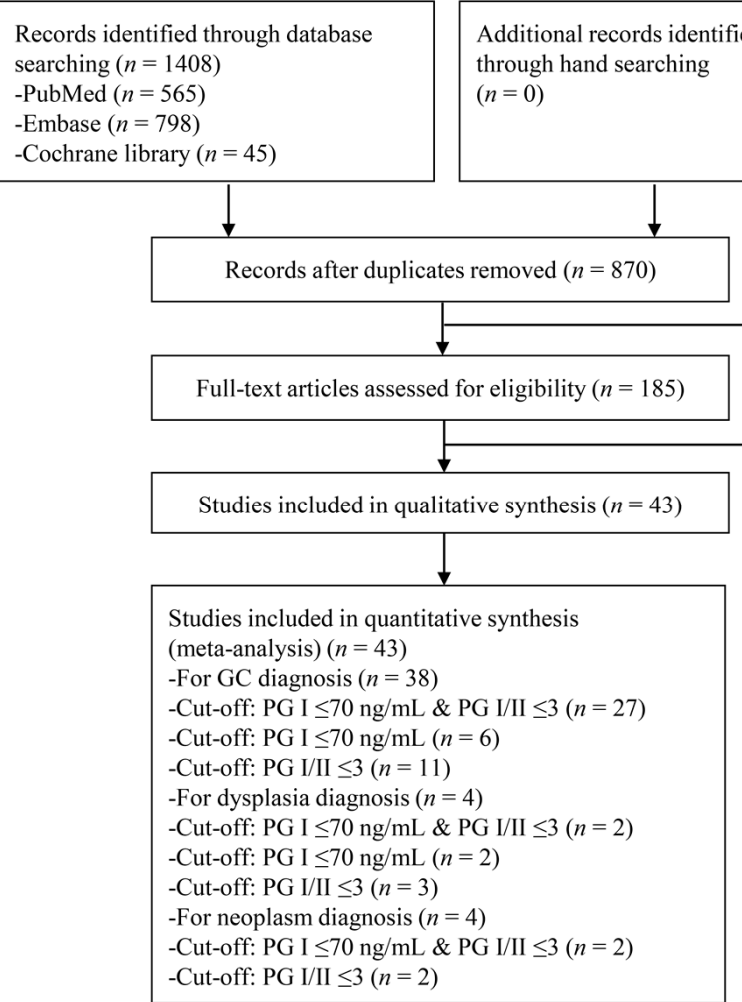

(B)

Figure 1. Flow diagram of the identification of relevant studies. (A) For the diagnosis of CAG, (B) For the diagnosis of gastric neoplasm. PG, pepsinogen; CAG, chronic atrophic gastritis.

Among the 38 studies for the diagnosis of GC, 28 studies [35-38,40-43,46,48-51,53,54,56-60,62,63,65,66,70-73] adopted the cut-off standard of PG I $\leq 70$ ng/mL and PG I/PG II ratio $\leq 3,11$ studies $[26,38,39,44,45,47,52,57,65,68,69]$ 
adopted the cut-off standard of PG I/PG II ratio $\leq 3$, and only six studies $[34,45,57,64,65,69]$ adopted the cut-off standard of $\mathrm{PG} \mathrm{I} \leq 70 \mathrm{ng} / \mathrm{mL}$.

Among the 28 studies that adopted the cut-off standard of PG I $\leq 70 \mathrm{ng} / \mathrm{mL}$ and PG I/PG II ratio $\leq 3$, two studies [46,51] evaluated diagnostic performance for sPGA based on same population with slightly different inclusion criteria. Therefore, to avoid dependence issue from single population-based multiple outcomes, the study with larger population [46] was included in the meta-analysis as a representative outcome. Finally, 27 studies were included for the diagnosis of GC with the cut-off standard of PG I $\leq 70 \mathrm{ng} / \mathrm{mL}$ and PG I/PG II ratio $\leq 3$.

\subsection{Characteristics of the Included Studies}

From the 14 studies [20-33] for the diagnosis of CAG, we identified a total of 5541 patients (2220 patients with CAG vs. 3321 patients without CAG). Among them, 11 [20,22-28,30-32] were case-control studies, whereas two [21,33] were cross-sectional studies and only one [29] was cohort study. Seven studies $[20,24,28-31,33]$ were conducted in Asia, whereas the remaining studies were conducted in Europe [21,22,26,27,32] and South America [23]. In 2009, Leja M et al. [25] reported enrollment of the population in Latvia, Lithuania, and Taiwan as an international study setting. The mean age of the enrolled population ranged from 43.6 to 66.3 years. Male predominance was detected in four studies $[24,26,28,31]$, whereas the remaining studies showed female predominance. For detection method of sPGA, most studies used enzyme-linked immunosorbent assay (ELISA), whereas three studies $[28,29,32]$ used latex-enhanced turbidimetric immunoassay (L-TIA) and two studies [20,26] deployed radioimmunoassay (RIA) (Table 3).

From the 43 studies [21,26,27,34-73] for the diagnosis of gastric neoplasm, we identified a total of 114,448 patients (4689 patients with GC, 430 patients with neoplasm, 130 patients with dysplasia vs. 109,199 patients without gastric neoplasm). Among them, 20 [26,27,34,36,37,40,43-45,54-58,61,62,64,67,68,72] were case-control studies, whereas 18 [35,39,41,42,46-51,53,59,60,63,66,69-71] were cohort studies, and only five $[21,38,52,65,73]$ were cross-sectional studies. Six studies $[21,26,27,59,70,73]$ were conducted in Europe, whereas the remaining 37 studies were conducted in Asia. The mean age of the enrolled population ranged from 33.4 to 68.2 years. Most of the studies showed male predominance except 11 studies $[21,27,38,42,53,59,60,66,67,70,73]$ showing female predominance. For detection of sPGA, most studies used RIA, whereas nine studies $[21,27,50,54,59,64,65,69,70]$ used ELISA, eight studies $[45,52,55,61,67,71-73]$ used L-TIA, four studies $[49,56,57,62]$ used chemiluminescent immunoassay (CLIA), two studies [43,68] used enzyme immunoassay (EIA), and one study [48] used either RIA or L-TIA (Table 4).

\subsection{Methodological Quality of the Include Studies}

Methodological qualities of the included studies were similar for the diagnosis of CAG except for five studies. Most of the studies used histological diagnosis as a reference standard of CAG diagnosis; however, three studies [20,28,31] deployed endoscopic diagnosis (visual inspection) as a reference standard of CAG diagnosis. One study [21] included only high-risk patients, such as patients with severe CAG, IM, and dysplasia, excluding the healthy population. Another study [33] also included high-risk patients as a population for reference standard. These five studies for the diagnosis of CAG were rated as "high-risk" in at least one of the seven domains (Figure 2). 
Table 3. Clinical characteristics of the included studies for the diagnosis of CAG.

\begin{tabular}{|c|c|c|c|c|c|c|c|c|c|c|c|c|c|c|}
\hline Study & $\begin{array}{c}\text { Study } \\
\text { Format/Nationality }\end{array}$ & Diagnosis & $\begin{array}{l}\text { Number of } \\
\text { Patients }\end{array}$ & $\begin{array}{c}\text { Number of } \\
\text { Control }\end{array}$ & Cut-off Value & $\begin{array}{c}\text { Detection } \\
\text { Method of } \\
\text { sPGA }\end{array}$ & $\begin{array}{l}\text { Age (Years, } \\
\text { Mean } \pm \text { SD) }\end{array}$ & Gender $(M / F)$ & Smoking & H. pylori & TP & FP & FN & $\mathrm{TN}$ \\
\hline $\begin{array}{l}\text { Inoue et al. } \\
\text { (1998) [20] }\end{array}$ & Case-control/Japan & $\begin{array}{c}\text { CAG (endoscopic } \\
\text { diagnosis without } \\
\text { histology) }\end{array}$ & 117 & 83 & $\begin{array}{c}\text { PG I } \leq 70 \mathrm{ng} / \mathrm{mL} \\
\text { and PG I/PG II ratio } \\
\leq 3\end{array}$ & RIA & $\begin{array}{c}\text { Mean } 60.5 \\
\text { (range: } 34-81 \text { ) }\end{array}$ & $91 / 109$ & & & 96 & 21 & 21 & 62 \\
\hline $\begin{array}{l}\text { Dinis-Ribeiro } \\
\text { et al. (2004) [21] }\end{array}$ & $\begin{array}{l}\text { Cross-sectional } \\
\text { /Portugal }\end{array}$ & $\begin{array}{l}\text { CAG with extensive } \\
\text { IM (histopathologic } \\
\text { evaluation of all three } \\
\text { specimens collected } \\
\text { demonstrated IM) } \\
\end{array}$ & 61 & 74 & PG I/PG II ratio $\leq 3$ & ELISA & $\begin{array}{c}\text { Median 61 } \\
\text { (range: } 26-75)\end{array}$ & Male: $36.8 \%$ & & & 40 & 16 & 21 & 58 \\
\hline $\begin{array}{l}\text { Nardone et al. } \\
(2005) \text { [22] }\end{array}$ & Case-control/Italy & $\begin{array}{c}\text { CAG (updated } \\
\text { Sydney classification) }\end{array}$ & 30 & 64 & PG I/PG II ratio $\leq 3$ & ELISA & $\begin{array}{c}\text { Mean 56 } \\
\text { (range: } 38-75 \text { ) }\end{array}$ & $36 / 58$ & & $44 / 94(46.8 \%)$ & 9 & 0 & 21 & 64 \\
\hline $\begin{array}{c}\text { Con et al. (2007) } \\
\text { [23] }\end{array}$ & $\begin{array}{c}\text { Case-control/Costa } \\
\text { Rica }\end{array}$ & $\begin{array}{c}\text { CAG (updated } \\
\text { Sydney classification) }\end{array}$ & 58 & 165 & $\begin{array}{c}\text { PG I } \leq 70 \mathrm{ng} / \mathrm{mL} \\
\text { and PG I/PG II } \leq 3\end{array}$ & ELISA & $51.17 \pm 12.8$ & $94 / 129$ & & $\begin{array}{c}91.4 \% \text { in patient } \\
\text { with CAG, } 68.5 \% \\
\text { in patient } \\
\text { without CAG }\end{array}$ & 45 & 64 & 13 & 101 \\
\hline $\begin{array}{l}\text { Iijima et al. } \\
\text { (2009) [24] }\end{array}$ & Case-control/Japan & CAG & 20 & 142 & $\begin{array}{c}\mathrm{PG} \mathrm{I} \leq 70 \mathrm{ng} / \mathrm{mL} \\
\text { and PG I/PG II ratio } \\
\leq 3\end{array}$ & ELISA & $\begin{array}{c}\text { Mean } 55 \\
\text { (range: 22-79) }\end{array}$ & $95 / 67$ & & & 15 & 44 & 5 & 98 \\
\hline 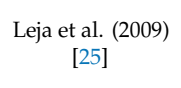 & $\begin{array}{l}\text { Case-control/Latvia, } \\
\text { Lithuania, Taiwan }\end{array}$ & $\begin{array}{l}\text { CAG (corpus, grade } \\
\text { II-III in updated } \\
\text { Sydney classification) }\end{array}$ & 24 & 217 & PG I/PG II ratio <3 & ELISA & $\begin{array}{c}\text { Mean 66.3 } \\
\text { (range: } 55-84 \text { ) }\end{array}$ & $68 / 173$ & & $165 / 241(68.5 \%)$ & 20 & 28 & 4 & 189 \\
\hline $\begin{array}{l}\text { Agkoc et al. } \\
\text { (2010) [26] }\end{array}$ & Case-control//Turkey & CAG & 30 & 110 & PG I/PG II ratio $<3$ & RIA & $\begin{array}{c}\text { CAG: } 60.56 \pm \\
\text { 11.29 (range: } \\
\text { 36-76) }\end{array}$ & $78 / 62$ & & & 26 & 7 & 4 & 103 \\
\hline \multirow[t]{3}{*}{$\begin{array}{l}\text { Yakut et al. } \\
\text { (2013) [27] }\end{array}$} & Case-control/Turkey & $\begin{array}{c}\text { CAG (updated } \\
\text { Sydney classification) }\end{array}$ & 45 & 117 & $\begin{array}{c}\mathrm{PG} \mathrm{I} \leq 70 \mathrm{ng} / \mathrm{mL} \\
\text { and PG I/PG II ratio } \\
\leq 3\end{array}$ & ELISA & $55.07 \pm 11.91$ & $75 / 87$ & $24(14.8 \%)$ & $98 / 162(60.5 \%)$ & 28 & 23 & 17 & 94 \\
\hline & & & & & PG I $\leq 70 \mathrm{ng} / \mathrm{mL}$ & & & & & & 28 & 22 & 17 & 95 \\
\hline & & & & & PG I/PG II ratio $\leq 3$ & & & & & & 26 & 12 & 19 & 105 \\
\hline $\begin{array}{c}\text { Lee et al. (2014) } \\
\text { [28] }\end{array}$ & Case-control/Korea & $\begin{array}{c}\text { CAG (endoscopic } \\
\text { diagnosis without } \\
\text { histology) }\end{array}$ & 1216 & 1204 & PG I/PG II ratio $\leq 3$ & L-TIA & Mean 57.6 & $1506 / 1052$ & & $1541(60.2 \%)$ & 775 & 471 & 441 & 733 \\
\hline \multirow[t]{2}{*}{$\begin{array}{l}\text { Kim et al. (2015) } \\
\text { [29] }\end{array}$} & Cohort/Korea & $\begin{array}{c}\text { CAG (updated } \\
\text { Sydney classification) } \\
\text { (antrum) }\end{array}$ & $22 / 95$ & & $\begin{array}{c}\mathrm{PG} \mathrm{I} \leq 70 \mathrm{ng} / \mathrm{mL} \\
\text { and PG I/PG II ratio } \\
\leq 3\end{array}$ & L-TIA & $57.7 \pm 12.1$ & $42 / 53$ & & $\begin{array}{c}12 / 31(38.7 \%) \\
\text { (in CAG) } 17 / 64 \\
(26.6 \%) \\
\text { (in no CAG) }\end{array}$ & 5 & 9 & 17 & 64 \\
\hline & & CAG (corpus) & $19 / 95$ & & & & & & & & 8 & 6 & 11 & 70 \\
\hline \multirow[t]{2}{*}{$\begin{array}{l}\text { Myint et al. } \\
\text { (2015) [30] }\end{array}$} & $\begin{array}{l}\text { Case-control } \\
\text { /Myanmar }\end{array}$ & $\begin{array}{l}\text { CAG (grade I-III in } \\
\text { updated Sydney } \\
\text { classification) }\end{array}$ & 143 & 109 & $\begin{array}{c}\mathrm{PG} \mathrm{I} \leq 70 \mathrm{ng} / \mathrm{mL} \\
\text { and PG I/PG II ratio } \\
\leq 3\end{array}$ & ELISA & $\begin{array}{c}43.6 \pm 14.2 \\
\text { (range: } 13-85 \text { ) }\end{array}$ & $97 / 155$ & & $121 / 252$ & 11 & 1 & 132 & 108 \\
\hline & & & & & PG I/PG II ratio $\leq 3$ & & & & & & 12 & 1 & 131 & 108 \\
\hline
\end{tabular}


Table 3. Cont.

\begin{tabular}{|c|c|c|c|c|c|c|c|c|c|c|c|c|c|c|}
\hline Study & $\begin{array}{c}\text { Study } \\
\text { Format/Nationality }\end{array}$ & Diagnosis & $\begin{array}{l}\text { Number of } \\
\text { Patients }\end{array}$ & $\begin{array}{c}\text { Number of } \\
\text { Control }\end{array}$ & Cut-off Value & $\begin{array}{l}\text { Detection } \\
\text { Method of } \\
\text { sPGA }\end{array}$ & $\begin{array}{l}\text { Age (Years, } \\
\text { Mean } \pm \text { SD) }\end{array}$ & Gender (M/F) & Smoking & H. pylori & TP & FP & FN & TN \\
\hline $\begin{array}{l}\text { Kotachi et al. } \\
\text { (2017) [31] }\end{array}$ & Case-control/Japan & $\begin{array}{r}\text { CAG (endoscopic } \\
\text { diagnosis without } \\
\text { histology) (corpus) }\end{array}$ & 370 & 170 & $\begin{array}{c}\mathrm{PG} \mathrm{I} \leq 70 \mathrm{ng} / \mathrm{mL} \\
\text { and PG I/PG II } \\
\text { ratio } \leq 3\end{array}$ & ELISA & Mean 61.2 & $375 / 165$ & & $217 / 540$ & 163 & 0 & 207 & 170 \\
\hline $\begin{array}{l}\text { Leja et al. (2017) } \\
\text { [32] }\end{array}$ & Case-control/Latvia & $\begin{array}{c}\text { CAG (grade II-III in } \\
\text { updated Sydney } \\
\text { classification) }\end{array}$ & 50 & 755 & $\begin{array}{c}\text { PG I } \leq 70 \mathrm{ng} / \mathrm{mL} \\
\text { and PG I/PG II ratio } \\
\leq 3\end{array}$ & L-TIA & $\begin{array}{l}\text { Median } 51 \\
\text { (range: 18-88) }\end{array}$ & $29 \%$ male & & & 38 & 235 & 12 & 520 \\
\hline \multirow[t]{2}{*}{$\begin{array}{l}\text { Loong et al. } \\
\text { (2017) [33] }\end{array}$} & $\begin{array}{l}\text { Cross-sectional } \\
\text { /Malaysia }\end{array}$ & $\begin{array}{l}\text { CAG or IM (updated } \\
\text { Sydney classification) } \\
\text { (corpus) }\end{array}$ & 37 & 35 & $\mathrm{PG} \mathrm{I} \leq 70 \mathrm{ng} / \mathrm{mL}$ & ELISA & $56.2 \pm 16.2$ & $33 / 39$ & & & 3 & 6 & 3 & 60 \\
\hline & & & & & PG I/PG II ratio $\leq 3$ & & & & & & 1 & 2 & 5 & 64 \\
\hline
\end{tabular}

sPGA, serum pepsinogen assay; M, male; F, female; SD, standard deviation; TP, true positive; FP, false positive; FN, false negative; TN, true negative; CAG, chronic atrophic gastritis; PG, pepsinogen; RIA, radioimmunoassay; IM, intestinal metaplasia; ELISA, enzyme-linked immunosorbent assay; L-TIA, latex-enhanced turbidimetric immunoassay.

Table 4. Clinical characteristics of the included studies for the diagnosis of GC.

\begin{tabular}{|c|c|c|c|c|c|c|c|c|c|c|c|c|c|c|}
\hline Study & $\begin{array}{c}\text { Study } \\
\text { Format/Nationality }\end{array}$ & Diagnosis & $\begin{array}{c}\text { Number of } \\
\text { Patients }\end{array}$ & $\begin{array}{c}\text { Number of } \\
\text { Control }\end{array}$ & Cut-off Value & $\begin{array}{l}\text { Detection } \\
\text { Method of } \\
\text { sPGA }\end{array}$ & $\begin{array}{l}\text { Age (Years, } \\
\text { Mean } \pm \text { SD) }\end{array}$ & Gender $(M / F)$ & Smoking & H. pylori & TP & FP & FN & $\mathrm{TN}$ \\
\hline $\begin{array}{l}\text { Chang et al. } \\
\text { (1992) [34] }\end{array}$ & Case-control/Taiwan & GC & 192 (175 AGC) & 70 & $\mathrm{PG} \mathrm{I} \leq 70 \mathrm{ng} / \mathrm{mL}$ & RIA & $\begin{array}{c}\text { GC: } 64.6 \pm 8.3 / \\
\text { control: } \\
51.2 \pm 11.2 \\
\text { range: } 32-85 \\
\end{array}$ & $235 / 27$ & $\begin{array}{l}112 / 262 \\
(42.7 \%)\end{array}$ & & 124 & 12 & 68 & 58 \\
\hline $\begin{array}{l}\text { Hattori et al. } \\
\text { (1995) [35] }\end{array}$ & $\begin{array}{c}\text { Cohort/Japan } \\
\text { (follow-up } \\
\text { duration: } 1 \text { year) }\end{array}$ & $\begin{array}{c}\text { GC }(100 \% \\
\text { adenocarcinoma; } 7 \\
\text { undifferentiated-and } 11 \\
\text { differentiated-type } \\
\text { histology) (sPGA } \\
\text { positive subjects were } \\
\text { screened by endoscopy) }\end{array}$ & $18 / 4876$ & & $\begin{array}{l}\text { PG I } \leq 70 \mathrm{ng} / \mathrm{mL} \\
\text { and PG I/PG II } \\
\text { ratio } \leq 3\end{array}$ & RIA & Range: 40-61 & $4761 / 115$ & & & 15 & 1243 & 3 & 3615 \\
\hline $\begin{array}{l}\text { Kodoi et al. } \\
\text { (1995) [36] }\end{array}$ & Case-control/Japan & GC & $\begin{array}{c}269(127 \mathrm{EGCs}, \\
142 \mathrm{AGCs} / 167 \\
\text { differentiated-, } \\
102 \\
\text { undifferentiated- } \\
\text { type histology) }\end{array}$ & $\begin{array}{l}1345 \text { (sex, age } \\
\text { matched) }\end{array}$ & $\begin{array}{l}\text { PG I }<70 \mathrm{ng} / \mathrm{mL} \text { and } \\
\text { PG I/PG II ratio }<3\end{array}$ & RIA & $\begin{array}{c}\text { GC: median } \\
65 \\
\text { (range: } 24-80 \text { ) }\end{array}$ & $1080 / 534$ & & & 162 & 543 & 107 & 802 \\
\hline $\begin{array}{l}\text { Watanabe et al. } \\
\text { (1997) [37] }\end{array}$ & $\begin{array}{c}\text { Nested } \\
\text { case-control/Japan }\end{array}$ & GC & 45 & $\begin{array}{l}225 \text { (sex-, age-, } \\
\text { and } \\
\text { address-matched } \\
\text { control) }\end{array}$ & $\begin{array}{l}\text { PG I } \leq 70 \mathrm{ng} / \mathrm{mL} \\
\text { and PG I/PG II } \\
\text { ratio } \leq 3\end{array}$ & RIA & & $156 / 114$ & & $211 / 270$ & 34 & 99 & 11 & 126 \\
\hline
\end{tabular}


Table 4. Cont.

\begin{tabular}{|c|c|c|c|c|c|c|c|c|c|c|c|c|c|c|}
\hline Study & $\begin{array}{c}\text { Study } \\
\text { Format/Nationality }\end{array}$ & Diagnosis & $\begin{array}{l}\text { Number of } \\
\text { Patients }\end{array}$ & $\begin{array}{l}\text { Number of } \\
\text { Control }\end{array}$ & Cut-off Value & $\begin{array}{l}\text { Detection } \\
\text { Method of } \\
\text { sPGA }\end{array}$ & $\begin{array}{c}\text { Age (Years, } \\
\text { Mean } \pm \text { SD) }\end{array}$ & Gender $(\mathrm{M} / \mathrm{F})$ & Smoking & H. pylori & TP & FP & FN & $\mathrm{TN}$ \\
\hline \multirow[t]{2}{*}{$\begin{array}{c}\text { Kitahara et al. } \\
\text { (1999) [38] }\end{array}$} & $\begin{array}{l}\text { Cross-sectional } \\
\text { /Japan }\end{array}$ & GC & $13 / 5113$ & & $\begin{array}{c}\text { PG I } \leq 70 \mathrm{ng} / \mathrm{mL} \\
\text { and PG I/PG II ratio } \\
\leq 3\end{array}$ & RIA & Mean 52.5 & $2456 / 2657$ & & & 11 & 1352 & 2 & 3748 \\
\hline & & & & & PG I/PG II ratio $\leq 3$ & & & & & & 11 & 1673 & 2 & 3427 \\
\hline $\begin{array}{l}\text { Dinis-Ribeiro } \\
\text { et al. (2004) [21] }\end{array}$ & $\begin{array}{l}\text { Cross-sectional } \\
\text { /Portugal }\end{array}$ & LGD & $23 / 136$ & & PG I/PG II ratio $\leq 3$ & ELISA & $\begin{array}{c}\text { Median 61 } \\
\text { (range: 26-75) }\end{array}$ & $50 / 86$ & & & 16 & 39 & 7 & 74 \\
\hline $\begin{array}{l}\text { Ohata et al. } \\
\text { (2004) [39] }\end{array}$ & $\begin{array}{l}\text { Cohort/Japan } \\
\text { (follow-up } \\
\text { duration: mean } 7.7 \\
\pm 0.9 \text { year) }\end{array}$ & $\begin{array}{l}\text { GC (Those with positive } \\
\text { double-contrast barium } \\
\text { X-ray and/or a positive } \\
\text { PG test were further } \\
\text { examined by endoscopy) }\end{array}$ & $45 / 4655$ & & PG I/PG II ratio $<3$ & RIA & $49.5 \pm 4.6$ & $100 \%$ male & & $3657 / 4655(78.6 \%)$ & 27 & 1585 & 18 & 3025 \\
\hline $\begin{array}{c}\text { Kim et al. (2005) } \\
\text { [40] }\end{array}$ & Case-control/Korea & GC & 13 & 30 & $\begin{array}{l}\text { PG I }<70 \mathrm{ng} / \mathrm{mL} \text { and } \\
\text { PG I/PG II ratio }<3\end{array}$ & RIA & $\begin{array}{c}\text { Normal } \\
\text { endoscopy } \\
\text { group: mean } \\
\text { 33.4, atrophic } \\
\text { gastritis: } 47.8 \\
\text { GC: } 57\end{array}$ & & & & 9 & 7 & 4 & 23 \\
\hline $\begin{array}{l}\text { Watabe et al. } \\
\text { (2005) [41] }\end{array}$ & $\begin{array}{c}\text { Cohort/Japan } \\
\text { (follow-up } \\
\text { duration: mean } 4.7 \\
\pm 1.7 \text { years) }\end{array}$ & GC & $\begin{array}{c}43 \text { (34 intestinal- } \\
\text { and } 9 \\
\text { diffuse-type } \\
\text { histology)/6983 }\end{array}$ & & $\begin{array}{c}\mathrm{PG} \mathrm{I} \leq 70 \mathrm{ng} / \mathrm{mL} \\
\text { and PG I/PG II } \\
\text { ratio } \leq 3\end{array}$ & RIA & $48.9 \pm 8.5$ & $4782 / 2201$ & & $\begin{array}{l}3216 / 6983(46.1 \%) \\
\text { in total, } 29 / 43 \\
(67.4 \%) \text { in GC }\end{array}$ & 30 & 1495 & 13 & 5445 \\
\hline $\begin{array}{l}\text { Oishi et al. } \\
\text { (2006) [42] }\end{array}$ & $\begin{array}{c}\text { Cohort/Japan } \\
\text { (follow-up } \\
\text { duration: } 14 \text { years) }\end{array}$ & GC & $89 / 2446$ & & $\begin{array}{l}\mathrm{PG} \mathrm{I} \leq 70 \mathrm{ng} / \mathrm{mL} \\
\text { and PG I/PG II } \\
\text { ratio } \leq 3\end{array}$ & RIA & $\begin{array}{l}\text { Mean } 57 \text { in } \\
\text { male and } 59 \\
\text { in female }\end{array}$ & $1016 / 1430$ & $\begin{array}{l}80.2 \% \text { in male } \\
\text { and } 8.2 \% \text { in } \\
\text { female }\end{array}$ & $\begin{array}{l}1745 / 2446(71.3 \%) \\
\text { in total and } 78 / 89 \\
(87.6 \%) \text { in GC }\end{array}$ & 53 & 661 & 36 & 1696 \\
\hline $\begin{array}{l}\text { Sasazuki et al. } \\
(2006)[43]\end{array}$ & $\begin{array}{c}\text { Nested } \\
\text { case-control/Japan }\end{array}$ & $\begin{array}{l}\text { GC (299 differentiated- } \\
\text { and 159 } 15 \\
\text { undifferentiated-type } \\
\text { histology) }\end{array}$ & 511 & $\begin{array}{l}511 \text { (matched } \\
\text { for gender, age, } \\
\text { study area, } \\
\text { blood donation } \\
\text { date, fasting } \\
\text { time at blood } \\
\text { donation) }\end{array}$ & $\begin{array}{c}\mathrm{PG} \mathrm{I} \leq 70 \mathrm{ng} / \mathrm{mL} \\
\text { and PG I/PG II } \\
\text { ratio } \leq 3\end{array}$ & EIA & $57.4 \pm 0.32$ & Male: $66.8 \%$ & $\begin{array}{c}\text { GC: } 35.7 \% \\
\text { control: } 30.3 \%\end{array}$ & & 419 & 295 & 92 & 216 \\
\hline $\begin{array}{l}\text { Sugiu et al. } \\
\text { (2006) [44] }\end{array}$ & Case-control/Japan & GC & 27 & 65 & PG I/PG II ratio $\leq 3$ & RIA & $\begin{array}{c}\text { Mean } 57.9 \\
\text { (range: } 15-88 \text { ) }\end{array}$ & $54 / 38$ & & $100 \%$ & 23 & 32 & 4 & 33 \\
\hline \multirow[t]{4}{*}{$\begin{array}{l}\text { Kang et al. } \\
\text { (2008) [45] }\end{array}$} & Case-control/Korea & GC & 380 & 626 & $\mathrm{PG} \mathrm{I} \leq 70 \mathrm{ng} / \mathrm{m}$ & L-TIA & $57.6 \pm 13.2$ & $585 / 421$ & & $788 / 1006(78.3 \%)$ & 275 & 500 & 105 & 126 \\
\hline & & GC & 380 & 626 & PG I/PG II ratio $\leq 3$ & & & & & & 225 & 244 & 155 & 382 \\
\hline & & Dysplasia & 107 & 899 & PG I $\leq 70 \mathrm{ng} / \mathrm{m}$ & & & & & & 88 & 717 & 19 & 182 \\
\hline & & Dysplasia & 107 & 899 & PG I/PG II ratio $\leq 3$ & & & & & & 66 & 351 & 41 & 548 \\
\hline $\begin{array}{l}\text { Yanaoka et al. } \\
(2008)[46]\end{array}$ & $\begin{array}{l}\text { Cohort/Japan } \\
\text { (follow-up } \\
\text { duration: mean } \\
9.7 \pm 0.9 \text { years) }\end{array}$ & $\begin{array}{l}\text { GC (Those with positive } \\
\text { double-contrast barium } \\
\text { X-ray and/or a positive } \\
\text { PG test were further } \\
\text { examined by endoscopy) }\end{array}$ & $63 / 5209$ & & $\begin{array}{c}\mathrm{PG} \mathrm{I} \leq 70 \mathrm{ng} / \mathrm{mL} \\
\text { and PG I/PG II } \\
\text { ratio } \leq 3\end{array}$ & RIA & $49.2 \pm 4.7$ & $100 \%$ male & & & 37 & 1370 & 26 & 3776 \\
\hline
\end{tabular}


Table 4. Cont.

\begin{tabular}{|c|c|c|c|c|c|c|c|c|c|c|c|c|c|c|}
\hline Study & $\begin{array}{c}\text { Study } \\
\text { Format/Nationality }\end{array}$ & Diagnosis & $\begin{array}{c}\text { Number of } \\
\text { Patients }\end{array}$ & $\begin{array}{l}\text { Number of } \\
\text { Control }\end{array}$ & Cut-off Value & $\begin{array}{l}\text { Detection } \\
\text { Method of } \\
\text { sPGA }\end{array}$ & $\begin{array}{l}\text { Age (Years, } \\
\text { Mean } \pm \text { SD) }\end{array}$ & Gender $(M / F)$ & Smoking & H. pylori & TP & FP & FN & TN \\
\hline $\begin{array}{l}\text { Yanaoka et al. } \\
\text { (2008) [47] }\end{array}$ & $\begin{array}{l}\text { Cohort/Japan } \\
\text { (follow-up } \\
\text { duration: mean } 9.7 \\
\pm 0.9 \text { years ) }\end{array}$ & $\begin{array}{l}\text { GC (Those with positive } \\
\text { double-contrast barium } \\
\text { X-ray and/or a positive } \\
\text { PG test were further } \\
\text { examined by endoscopy) }\end{array}$ & $63 / 5209$ & & PG I/PG II ratio $\leq 3$ & RIA & $49.2 \pm 4.7$ & $100 \%$ male & & $3656 / 5209$ & 43 & 1713 & 20 & 3433 \\
\hline $\begin{array}{l}\text { Miki et al. } \\
\text { (2009) [48] }\end{array}$ & $\begin{array}{c}\text { Cohort/Japan } \\
\text { (follow-up } \\
\text { duration: } 15 \text { year) }\end{array}$ & $\begin{array}{c}\text { GC including } \\
\text { intramucosal cancers } \\
\text { (Those with a positive } \\
\text { PG test and those with a } \\
\text { negative PG test took } \\
\text { endoscopy every } 2 \text { and } 5 \\
\text { years, respectively) }\end{array}$ & $\begin{array}{c}125 \text { (28 EGCs, } \\
72 \text { intramucosal } \\
\text { cancers, } 25 \\
\text { AGCs)/13789 }\end{array}$ & & $\begin{array}{c}\mathrm{PG} \mathrm{I} \leq 70 \mathrm{ng} / \mathrm{mL} \\
\text { and PG I/PG II } \\
\text { ratio } \leq 3\end{array}$ & RIA or L-TIA & Mean 48.7 & $\begin{array}{c}\text { Initial } \\
\text { enrollment: } \\
\text { 101,892 } \\
(85,578 / 16,314)\end{array}$ & & & 110 & 9026 & 15 & 4638 \\
\hline $\begin{array}{l}\text { Mizuno et al. } \\
\text { (2009) [49] }\end{array}$ & $\begin{array}{c}\text { Cohort/Japan } \\
\text { (follow-up } \\
\text { duration: } 1 \text { year) }\end{array}$ & $\begin{array}{l}\text { GC (PG I level of } \leq 30 \\
\text { ng/mL and a PG I/PG II } \\
\text { ratio of } \leq 2.0 \text { or those } \\
\text { with abnormal X-ray } \\
\text { findings were advised to } \\
\text { undergo endoscopy) }\end{array}$ & $19 / 12120$ & & $\begin{array}{c}\mathrm{PG} \mathrm{I} \leq 70 \mathrm{ng} / \mathrm{mL} \\
\text { and PG I/PG II } \\
\text { ratio } \leq 3\end{array}$ & CLIA & $\begin{array}{l}\text { Male: median } \\
50 \text { (range: } \\
15-84), \\
\text { Female: } \\
\text { median 49 } \\
\text { (range: 22-84) }\end{array}$ & $7590 / 4530$ & & & 13 & 1743 & 6 & 10,358 \\
\hline $\begin{array}{l}\text { Yamaji et al. } \\
\text { (2009) [50] }\end{array}$ & $\begin{array}{l}\text { Cohort/Japan } \\
\text { (follow-up } \\
\text { duration: mean } \\
\text { 4.79 years) } \\
\end{array}$ & GC & $37 / 6158$ & & $\begin{array}{c}\mathrm{PG} \mathrm{I} \leq 70 \mathrm{ng} / \mathrm{mL} \\
\text { and PG I/PG II } \\
\text { ratio } \leq 3\end{array}$ & ELISA & Mean 49 & $4259 / 1899$ & $\begin{array}{c}2177 / 6158 \\
\text { (current or } \\
\text { past smoker) }\end{array}$ & 2901/6158 & 27 & 1333 & 10 & 4788 \\
\hline $\begin{array}{l}\text { Yanaoka et al. } \\
\text { (2009) [51] }\end{array}$ & $\begin{array}{c}\text { Cohort/Japan } \\
\text { (follow-up } \\
\text { duration: mean } 9.3 \\
\pm 0.7 \text { years) }\end{array}$ & $\begin{array}{l}\text { GC (Those with positive } \\
\text { double-contrast barium } \\
\text { X-ray and/or a positive } \\
\text { PG test were further } \\
\text { examined by endoscopy) }\end{array}$ & $\begin{array}{c}60 \text { (40 intestinal- } \\
\text { and } 20 \\
\text { diffuse-type } \\
\text { histology)/4129 } \\
(3,656 \text { with } \\
\text { persistent } H . \\
\text { pylori infection } \\
\text { and } 473 \text { with } \\
\text { successful } H . \\
\text { pylori } \\
\text { eradication })\end{array}$ & & $\begin{array}{c}\mathrm{PG} \mathrm{I} \leq 70 \mathrm{ng} / \mathrm{mL} \\
\text { and PG I/PG II } \\
\text { ratio } \leq 3\end{array}$ & RIA & $\begin{array}{l}49.8 \pm 4.6 \text { in } \\
\text { H. pylori } \\
\text { infection } \\
\text { group, } \\
49.6 \pm 5.5 \text { in } \\
\text { eradication } \\
\quad \text { group }\end{array}$ & $100 \%$ male & $\begin{array}{l}57.1 \% \text { in } H . \\
\text { pylori } \\
\text { infection } \\
\text { group, } 55.4 \% \\
\text { in eradication } \\
\text { group }\end{array}$ & $100 \%$ infected & 28 & 1050 & 32 & 3019 \\
\hline $\begin{array}{l}\text { Agkoc et al. } \\
\text { (2010) [26] }\end{array}$ & Case-control/Turkey & GC & 50 & 90 & PG I/PG II ratio $<3$ & RIA & $\begin{array}{c}\text { GC: } 65.42 \pm \\
\text { 10.28 (range: } \\
\text { 38-83) }\end{array}$ & $78 / 62$ & & & 42 & 9 & 8 & 81 \\
\hline $\begin{array}{l}\text { Kwak et al. } \\
\text { (2010) [52] }\end{array}$ & Cross-sectional/Korea & GC & 460 & 460 & PG I/PG II ratio $\leq 3$ & L-TIA & Mean 57.9 & $528 / 392$ & & $765(83.2 \%)$ & 244 & 136 & 216 & 324 \\
\hline $\begin{array}{l}\text { Mizun et al. } \\
\text { (2010) [53] }\end{array}$ & $\begin{array}{c}\text { Cohort/Japan } \\
\text { (follow-up } \\
\text { duration: median } \\
9.3 \text { years) }\end{array}$ & GC & $61 / 2859$ & & $\begin{array}{c}\text { PG I } \leq 70 \mathrm{ng} / \mathrm{mL} \\
\text { and PG I/PG II } \\
\text { ratio } \leq 3\end{array}$ & RIA & $\begin{array}{c}55-74 \\
\text { category is } \\
\text { most } \\
\text { prevalent }\end{array}$ & $1011 / 1848$ & & $2148 / 2859$ & 44 & 1079 & 17 & 1719 \\
\hline
\end{tabular}


Table 4. Cont

\begin{tabular}{|c|c|c|c|c|c|c|c|c|c|c|c|c|c|c|}
\hline Study & $\begin{array}{c}\text { Study } \\
\text { Format/Nationality }\end{array}$ & Diagnosis & $\begin{array}{l}\text { Number of } \\
\text { Patients }\end{array}$ & $\begin{array}{l}\text { Number of } \\
\text { Control }\end{array}$ & Cut-off Value & $\begin{array}{c}\text { Detection } \\
\text { Method of } \\
\text { sPGA }\end{array}$ & $\begin{array}{l}\text { Age (Years, } \\
\text { Mean } \pm \text { SD) }\end{array}$ & Gender $(\mathrm{M} / \mathrm{F})$ & Smoking & H. pylori & TP & FP & FN & $\mathrm{TN}$ \\
\hline $\begin{array}{l}\text { Aikou et al. } \\
\text { (2011) [54] }\end{array}$ & Case-control/Japan & GC & $\begin{array}{l}183(107 \text { AGCs, } \\
76 \text { EGCs; } 86 \\
\text { differentiated- } \\
\text { and } 97 \\
\text { undifferentiated-type } \\
\text { EGCs) }\end{array}$ & 269 & $\begin{array}{l}\text { PG I }<70 \mathrm{ng} / \mathrm{mL} \text { and } \\
\text { PG I/PG II ratio }<3\end{array}$ & ELISA & $\begin{array}{c}\text { GC: } \\
66.0 \pm 10.7 / \\
\text { control: } \\
50.1 \pm 9.9\end{array}$ & $362 / 90$ & & $\begin{array}{c}\text { GC: } 62.3 \%, \\
\text { control: } 34.9 \%\end{array}$ & 82 & 34 & 101 & 235 \\
\hline $\begin{array}{l}\text { Chang et al. } \\
\text { (2011) [55] }\end{array}$ & Case-control/Korea & Gastric neoplasms & $\begin{array}{l}297(61 \text { LGDs, } \\
21 \text { HGDs, } 84 \\
\text { EGCs, 131 } \\
\text { AGCs) }\end{array}$ & 293 & PG I/PG II ratio $\leq 3$ & L-TIA & $\begin{array}{c}\text { LGD: } \\
60.2 \pm 9.5 \\
\text { HGD: } \\
63.1 \pm 8.6 \\
\text { EGC: } \\
59.8 \pm 9.2 \\
\text { AGC: } \\
61.6 \pm 12.6 \\
\text { control: } \\
50.7 \pm 13.6 \\
\end{array}$ & $368 / 222$ & $\begin{array}{c}\text { Gastric } \\
\text { neoplasms: } \\
\text { 22.8-51.9\%\% } \\
\text { control: } 24.2 \%\end{array}$ & $\begin{array}{c}\text { Gastric } \\
\text { neoplasms: } \\
60.7-81 \% \text {, control: } \\
58 \%\end{array}$ & 184 & 89 & 113 & 204 \\
\hline $\begin{array}{l}\text { Kaise et al. } \\
\text { (2011) [56] }\end{array}$ & Case-control/Japan & GC & 192 & 1254 & $\begin{array}{c}\mathrm{PG} \mathrm{I} \leq 70 \mathrm{ng} / \mathrm{mL} \\
\text { and PG I/PG II } \\
\text { ratio } \leq 3\end{array}$ & CLIA & $\begin{array}{c}\text { GC: } \\
64.3 \pm 9.7 / \\
\text { control: } \\
52.3 \pm 12.4 \\
\end{array}$ & $\begin{array}{c}\text { GC: } 5: 1, \\
\text { control: } 1.2: 1\end{array}$ & $\begin{array}{c}\text { GC: } 63 \% \\
\text { control: } 38.2 \%\end{array}$ & $\begin{array}{c}\text { GC: } 83.9 \%, \\
\text { control: } 30.1 \%\end{array}$ & 129 & 229 & 63 & 1025 \\
\hline \multirow[t]{3}{*}{$\begin{array}{l}\text { Kikuchi et al. } \\
\text { (2011) [57] }\end{array}$} & Case-control/Japan & EGC & $\begin{array}{l}122(114 \text { well- to } \\
\text { moderate-differentiated } \\
\text { EGCs and } 8 \\
\text { poorly-differentiated } \\
\text { EGCs) }\end{array}$ & ed 178 & $\begin{array}{c}\mathrm{PG} \mathrm{I} \leq 70 \mathrm{ng} / \mathrm{mL} \\
\text { and PG I/PG II } \\
\text { ratio } \leq 3\end{array}$ & CLIA & $\begin{array}{c}\text { GC: } \\
68.2 \pm 9.7 / \\
\text { control: } \\
56.2 \pm 14.9\end{array}$ & $187 / 113$ & & $\begin{array}{l}\text { GC: } 100 / 122 \\
\text { (82\%), control: } \\
109 / 178(61.2 \%)\end{array}$ & 95 & 68 & 27 & 110 \\
\hline & & & & & PG I $\leq 70$ ng/mL & & & & & & 114 & 148 & 8 & 30 \\
\hline & & & & & PG I/PG II ratio $\leq 3$ & & & & & & 100 & 83 & 22 & 95 \\
\hline $\begin{array}{c}\text { Ito et al. (2012) } \\
\text { [58] }\end{array}$ & Case-control/Japan & Diffuse-type EGC & 42 & 511 & $\begin{array}{l}\mathrm{PG} \mathrm{I} \leq 70 \mathrm{ng} / \mathrm{mL} \\
\text { and PG I/PG II } \\
\text { ratio } \leq 3\end{array}$ & RIA & $\begin{array}{c}\text { GC: mean } \\
57.2 \text { in male, } \\
59.1 \text { in female. } \\
\text { Control: } \\
\text { mean } 58.5\end{array}$ & $305 / 248$ & & $387 / 553$ & 20 & 191 & 22 & 320 \\
\hline $\begin{array}{l}\text { Lomba-Viana } \\
\text { et al. (2012) [59] }\end{array}$ & $\begin{array}{l}\text { Cohort/Portugal } \\
\text { (follow-up } \\
\text { duration: 3-5 year) }\end{array}$ & GC & $\begin{array}{c}6 \text { (5 intestinal- } \\
\text { and } 1 \\
\text { diffuse-type } \\
\text { histology/3 } \\
\text { EGCs and } 3 \\
\text { AGCs)/514 }\end{array}$ & & $\begin{array}{c}\mathrm{PG} \mathrm{I} \leq 70 \mathrm{ng} / \mathrm{mL} \\
\text { and PG I/PG II ratio } \\
\leq 3\end{array}$ & ELISA & $\begin{array}{l}\text { Median } 60 \\
\text { (range: } 40-79 \text { ) }\end{array}$ & $76 / 438$ & & 165/514 (32.1\%) & 6 & 268 & 3 & 237 \\
\hline $\begin{array}{l}\text { Zhang et al. } \\
\text { (2012) [60] }\end{array}$ & $\begin{array}{c}\text { Cohort/China } \\
\text { (follow-up } \\
\text { duration: } 14 \text { years) }\end{array}$ & GC & $26 / 1501$ & & $\begin{array}{c}\mathrm{PG} \mathrm{I} \leq 70 \mathrm{ng} / \mathrm{mL} \\
\text { and PG I/PG II ratio } \\
\leq 3\end{array}$ & RIA & $45.29 \pm 12.18$ & $554 / 947$ & & $995 / 1501(66.3 \%)$ & 9 & 158 & 17 & 1317 \\
\hline \multirow[t]{3}{*}{$\begin{array}{l}\text { Yakut et al. } \\
\text { (2013) [27] }\end{array}$} & Case-control//Turkey & Dysplasia & 37 & 125 & $\begin{array}{c}\mathrm{PG} \mathrm{I} \leq 70 \mathrm{ng} / \mathrm{mL} \\
\text { and PG I/PG II ratio } \\
\leq 3\end{array}$ & ELISA & $57.52 \pm 11.16$ & $75 / 87$ & $24(14.8 \%)$ & $98 / 162(60.5 \%)$ & 13 & 38 & 24 & 87 \\
\hline & & & & & $\mathrm{PG} \mathrm{I} \leq 70 \mathrm{ng} / \mathrm{mL}$ & & & & & & 13 & 37 & 24 & 88 \\
\hline & & & & & PG I/PG II ratio $\leq 3$ & & & & & & 8 & 30 & 29 & 95 \\
\hline
\end{tabular}


Table 4. Cont

\begin{tabular}{|c|c|c|c|c|c|c|c|c|c|c|c|c|c|c|}
\hline Study & $\begin{array}{c}\text { Study } \\
\text { Format/Nationality }\end{array}$ & Diagnosis & $\begin{array}{l}\text { Number of } \\
\text { Patients }\end{array}$ & $\begin{array}{l}\text { Number of } \\
\text { Control }\end{array}$ & Cut-off Value & $\begin{array}{l}\text { Detection } \\
\text { Method of } \\
\text { sPGA }\end{array}$ & $\begin{array}{l}\text { Age (Years, } \\
\text { Mean } \pm \text { SD) }\end{array}$ & Gender $(\mathrm{M} / \mathrm{F})$ & Smoking & H. pylori & TP & FP & FN & $\mathrm{TN}$ \\
\hline $\begin{array}{l}\text { Choi et al. } \\
\text { (2014) [61] }\end{array}$ & Case-control/Korea & Gastric neoplasms & 17 & 3311 & $\begin{array}{c}\text { PG I } \leq 70 \mathrm{ng} / \mathrm{mL} \\
\text { and PG I/PG II } \\
\text { ratio } \leq 3\end{array}$ & L-TIA & $\begin{array}{c}\text { Mean } \\
49.8-59.0\end{array}$ & 1979/1349 & & & 9 & 438 & 8 & 2873 \\
\hline $\begin{array}{l}\text { Huang et al. } \\
\text { (2014) [62] }\end{array}$ & $\begin{array}{c}\text { Nested } \\
\text { case-control/China }\end{array}$ & GC & 72 & 37 & $\begin{array}{c}\mathrm{PG} \mathrm{I} \leq 70 \mathrm{ng} / \mathrm{mL} \\
\text { and PG I/PG II } \\
\text { ratio } \leq 3\end{array}$ & CLIA & $\begin{array}{c}\text { GC: } 61.7 \pm 1.4 \\
\text { control: } \\
56.7 \pm 2.8\end{array}$ & $\begin{array}{c}\text { GC: } 1.23: 1 . \\
\text { Control: } \\
1.31: 1\end{array}$ & & $\begin{array}{c}\text { GC: } 66.7 \% \\
\text { control: } 48 \%\end{array}$ & 27 & 7 & 45 & 30 \\
\hline $\begin{array}{l}\text { Yoshida et al. } \\
\text { (2014) [63] }\end{array}$ & $\begin{array}{l}\text { Cohort/Japan } \\
\text { (follow-up } \\
\text { duration: mean } \\
11.6 \pm 4.3 \text { years) }\end{array}$ & $\begin{array}{l}\text { GC (those with positive } \\
\text { double-contrast barium } \\
\text { X-ray and/or a positive } \\
\text { PG test were further } \\
\text { examined by endoscopy) }\end{array}$ & $87 / 4655$ & & $\begin{array}{c}\mathrm{PG} \mathrm{I} \leq 70 \mathrm{ng} / \mathrm{mL} \\
\text { and PG I/PG II } \\
\text { ratio } \leq 3\end{array}$ & RIA & $49.5 \pm 4.6$ & $100 \%$ male & $59.3 \%$ & $3657 / 4655$ & 48 & 1314 & 39 & 3254 \\
\hline \multirow[t]{2}{*}{$\begin{array}{l}\text { Zhang et al. } \\
\text { (2014) [64] }\end{array}$} & Case-control/China & GC & $\begin{array}{c}82 \text { (69 AGCs, } 13 \\
\text { EGCs) }\end{array}$ & 142 & $\mathrm{PG} \mathrm{I} \leq 70 \mathrm{ng} / \mathrm{mL}$ & ELISA & $\begin{array}{l}\text { Patients with } \\
\text { gastrointestinal } \\
\text { diseases: } \\
52.3 \pm 12.3 \\
\text { (range 19-80), } \\
\text { control: } \\
52.4 \pm 15.1 \\
\text { (range 29-77) }\end{array}$ & $163 / 85$ & $\begin{array}{l}85.4 \% \text { in } \\
\text { patients with } \\
\text { GC, } 74.4 \% \text { in } \\
\text { control }\end{array}$ & & 56 & 25 & 26 & 117 \\
\hline & & & & & PG I/PG II ratio $\leq 3$ & & & & & & 21 & 2 & 61 & 140 \\
\hline \multirow[t]{3}{*}{$\begin{array}{l}\text { Eybpoosh et al. } \\
\text { (2015) [65] }\end{array}$} & Cross-sectional/Iran & GC & $\begin{array}{c}578 \text { (62 EGCs, } \\
516 \text { AGCs/315 } \\
\text { intestinal-, } 203 \\
\text { diffuse-, } 69 \\
\text { mixed-type } \\
\text { histology/274 } \\
\text { undifferentiated-, } \\
304 \\
\text { differentiated-type } \\
\text { histology) }\end{array}$ & 763 & $\begin{array}{c}\mathrm{PG} \mathrm{I} \leq 70 \mathrm{ng} / \mathrm{mL} \\
\text { and PG I/PG II } \\
\text { ratio } \leq 3\end{array}$ & ELISA & & $750 / 591$ & $399 / 1341$ & & 100 & 44 & 478 & 719 \\
\hline & & & & & PG I $\leq 70 \mathrm{ng} / \mathrm{mL}$ & & & & & & 133 & 234 & 445 & 529 \\
\hline & & & & & PG I/PG II ratio $\leq 3$ & & & & & & 32 & 34 & 546 & 729 \\
\hline $\begin{array}{l}\text { Ikeda et al. } \\
\text { (2016) [66] }\end{array}$ & $\begin{array}{c}\text { Cohort/Japan } \\
\text { (follow-up: at least } \\
20 \text { years) } \\
\end{array}$ & GC & $123 / 2446$ & & $\begin{array}{c}\mathrm{PG} \mathrm{I} \leq 70 \mathrm{ng} / \mathrm{mL} \\
\text { and PG I/PG II } \\
\text { ratio } \leq 3 \\
\end{array}$ & RIA & $58.3 \pm 11.4$ & 1016/1430 & $24.6 \%$ & $1761 / 2446$ & 70 & 644 & 53 & 1679 \\
\hline $\begin{array}{c}\text { Cho et al. (2017) } \\
\text { [67] }\end{array}$ & Case-control/Korea & Gastric neoplasms & $\begin{array}{c}87 \text { (19 LGDs, } 16 \\
\text { HGDs, } 40 \text { EGCs, } \\
12 \text { AGCs) }\end{array}$ & 311 & PG I/PG II ratio $\leq 3$ & L-TIA & $48.2 \pm 16.6$ & $170 / 228$ & & $\begin{array}{l}\text { 209/398 (52.5\%) } \\
(46 \% \text { with } \\
\text { neoplasm vs. } \\
75.9 \% \text { without } \\
\text { neoplasm) }\end{array}$ & 59 & 62 & 28 & 249 \\
\hline
\end{tabular}


Table 4. Cont.

\begin{tabular}{|c|c|c|c|c|c|c|c|c|c|c|c|c|c|c|}
\hline Study & $\begin{array}{c}\text { Study } \\
\text { Format/Nationality }\end{array}$ & Diagnosis & $\begin{array}{l}\text { Number of } \\
\text { Patients }\end{array}$ & $\begin{array}{c}\text { Number of } \\
\text { Control }\end{array}$ & Cut-off Value & $\begin{array}{c}\text { Detection } \\
\text { Method of } \\
\text { sPGA }\end{array}$ & $\begin{array}{l}\text { Age (Years, } \\
\text { Mean } \pm \text { SD) }\end{array}$ & Gender $(M / F)$ & Smoking & H. pylori & TP & FP & FN & $\mathrm{TN}$ \\
\hline $\begin{array}{l}\text { Hamashima } \\
\text { et al. (2017) [68] }\end{array}$ & $\begin{array}{c}\text { Nested } \\
\text { case-control/Japan }\end{array}$ & GC & 497 & $\begin{array}{c}497 \text { (matched } \\
\text { for sex, age, } \\
\text { blood donation } \\
\text { date, and } \\
\text { fasting time at } \\
\text { blood donation) }\end{array}$ & PG I/PG II ratio $\leq 3$ & EIA & $57.5 \pm 7.2$ & Male: $66.4 \%$ & & & 432 & 299 & 65 & 198 \\
\hline \multirow[t]{2}{*}{$\begin{array}{c}\text { Tu et al. (2017) } \\
\text { [69] }\end{array}$} & $\begin{array}{l}\text { Cohort/China } \\
\text { (follow-up } \\
\text { duration: median } \\
11.6 \text { years) } \\
\end{array}$ & GC & $86 / 12018$ & & $\mathrm{PG} \mathrm{I} \leq 70 \mathrm{ng} / \mathrm{mL}$ & ELISA & $\begin{array}{c}\text { GC: } 59.0 \pm \\
\text { 10.6/GC-free: } \\
49.6 \pm 10.7\end{array}$ & $\begin{array}{l}82.6 \% \text { male in } \\
\text { GC/45.1\% } \\
\text { male in } \\
\text { GC-free }\end{array}$ & $\begin{array}{l}39 \% \text { in } \\
\text { GC/36.4\% in } \\
\text { GC-free }\end{array}$ & & 27 & 3642 & 59 & 8290 \\
\hline & & & & & PG I/PG II ratio <3 & & & & & & 15 & 728 & 71 & 11204 \\
\hline $\begin{array}{l}\text { Castro et al. } \\
\text { (2018) [70] }\end{array}$ & $\begin{array}{c}\text { Cohort/Portugal } \\
\text { (follow-up } \\
\text { duration: median } \\
6.5 \text { years for sPGA } \\
(+) / 7.5 \text { years for } \\
\text { sPGA (-) }\end{array}$ & $\begin{array}{c}\text { GC (100\% } \\
\text { adenocarcinoma) }\end{array}$ & $26 / 5913$ & & $\begin{array}{c}\text { PG I } \leq 70 \mathrm{ng} / \mathrm{mL} \\
\text { and PG I/PG II } \\
\text { ratio } \leq 3\end{array}$ & ELISA & Range: 40-74 & $2257 / 3656$ & & & 9 & 216 & 17 & 5671 \\
\hline \multirow[t]{2}{*}{$\begin{array}{l}\text { Kwak et al. } \\
\text { (2018) [71] }\end{array}$} & $\begin{array}{c}\text { Cohort/Korea } \\
\text { (follow-up } \\
\text { duration: mean } 5.6 \\
\text { years) }\end{array}$ & GC & $15 / 3297$ & & $\begin{array}{l}\text { PG I } \leq 70 \mathrm{ng} / \mathrm{mL} \\
\text { and PG I/PG II } \\
\text { ratio } \leq 3\end{array}$ & L-TIA & $51.3 \pm 9.4$ & 2326/971 & & 2020/3297 & 7 & 567 & 8 & 2715 \\
\hline & & Gastric neoplasms & $29 / 3297$ & & & & & & & & 12 & 562 & 17 & 2706 \\
\hline $\begin{array}{l}\text { Lee et al. (2018) } \\
\text { [72] }\end{array}$ & Case-control/Korea & EGC & 30 & 30 & $\begin{array}{l}\mathrm{PG} \mathrm{I}<70 \mathrm{ng} / \mathrm{mL} \text { and } \\
\text { PG I/PG II ratio }<3\end{array}$ & L-TIA & $\begin{array}{c}59.5 \pm 10.7 \\
\text { (patients with } \\
\text { EGC) vs. } 66.6 \\
\pm 12.0 \\
\text { (control) }\end{array}$ & $36 / 24$ & & & 10 & 2 & 20 & 28 \\
\hline \multirow[t]{2}{*}{$\begin{array}{c}\text { Sjomina et al. } \\
(2018)[73]\end{array}$} & Cross-sectional/Latvia & GC & 2 & 257 & $\begin{array}{l}\text { PG I }<70 \mathrm{ng} / \mathrm{mL} \text { and } \\
\text { PG I/PG II ratio }<3\end{array}$ & L-TIA & $56.5 \pm 12.5$ & $82 / 177$ & & $177(66 \%)$ & 1 & 160 & 1 & 97 \\
\hline & & Gastric dysplasia & 21 & 238 & & & & & & & 17 & 144 & 4 & 94 \\
\hline
\end{tabular}

sPGA, serum pepsinogen assay; M, male; F, female; SD, standard deviation; TP, true positive; FP, false positive; FN, false negative; TN, true negative; GC, gastric cancer; EGC, early gastric cancer; AGC, advanced gastric cancer; LGD, low grade dysplasia; HGD, high grade dysplasia; PG, pepsinogen; RIA, radioimmunoassay; EIA, enzyme immunoassay; CLIA, chemiluminescent immunoassay; ELISA, enzyme-linked immunosorbent assay; L-TIA, latex-enhanced turbidimetric immunoassay. 


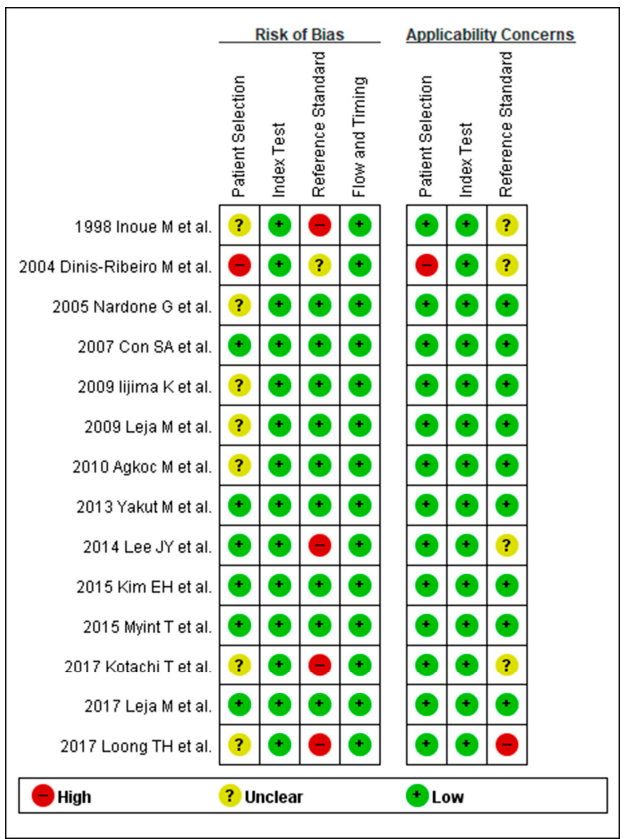

Figure 2. QUADAS-2 for the assessment of the methodological qualities of all the enrolled studies for the diagnosis of CAG. (+) denotes low risk of bias, (?) denotes unclear risk of bias, (-) denotes high risk of bias. QUADAS-2, Quality Assessment of Diagnostic Accuracy Studies-2; CAG, chronic atrophic gastritis.

Methodological qualities of the included studies were similar for the diagnosis of gastric neoplasm except for 13 studies. Ideally, all the patients should be tested with the same reference standard method (endoscopy). However, seven studies $[35,39,46,47,49,51,63]$ performed endoscopy to diagnose gastric neoplasm only for patients with positive sPGA or positive double-contrast barium X-ray introducing partial verification bias. One study [48] conducted endoscopy every 2 years for patients with positive sPGA and every 5 years for patients with negative sPGA, adopting different standards of reference test (differential verification bias).

Five studies $[39,46,47,51,63]$ included only male patients, one study [44] included only patients with $H$. pylori infection, two studies [57,72] included only patients with early GC, and one study [58] included only patients with diffuse-type GC.

Two studies [46,51] evaluated diagnostic performance of sPGA based on a same population with slightly different inclusion criteria and another two studies [46,47] also evaluated diagnostic performance based on a same population using different cut-off values. Therefore, these studies were ranked as "high-risk" for the applicability concerns.

Since most of the studies were case-control studies, they were not ranked as "high-risk". A total of 13 abovementioned studies for the diagnosis of gastric neoplasm were rated as "high-risk" in at least one of the seven domains (Figure 3).

\subsection{DTA of sPGA in $C A G$}

Values for sensitivity, specificity, PLR, NLR, DOR, and area under the curve (AUC) with $95 \%$ CI for the cut-off value of PG I $\leq 70 \mathrm{ng} / \mathrm{mL}$ and PG I/PG II ratio $\leq 3$ for CAG diagnosis were $0.59(95 \% \mathrm{CI}$ : $0.38-0.78), 0.89(0.70-0.97), 5.5(2.3-13.0), 0.46(0.30-0.69), 12$ (6-25), and 0.81 (0.77-0.84), respectively (Table 5, Figure 4A). The SROC curve with 95\% confidence region and prediction region is illustrated in Figure 5A. To investigate the clinical utility of sPGA, Fagan's nomogram was generated. Assuming $20 \%$ prevalence of CAG (prior probability), Fagan's nomogram shows that the posterior probability of CAG is $58 \%$ if patients are diagnosed as positive, and the posterior probability of CAG is $10 \%$ if 
patients are diagnosed as negative according to the sPGA with the cut-off value of PG I $\leq 70 \mathrm{ng} / \mathrm{mL}$ and PG I/PG II ratio $\leq 3$ (Figure 6A).

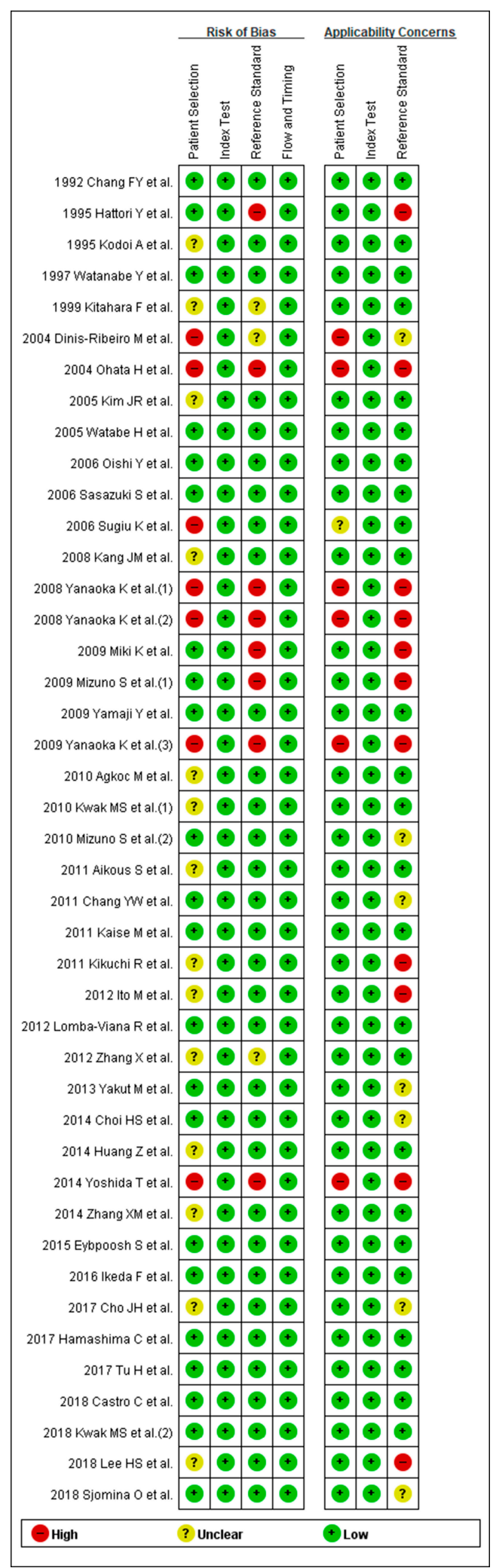

Figure 3. QUADAS-2 for the assessment of the methodological qualities of all the enrolled studies for the diagnosis of gastric neoplasm. (+) denotes low risk of bias, (?) denotes unclear risk of bias, (-) denotes high risk of bias. QUADAS-2, Quality Assessment of Diagnostic Accuracy Studies-2. 
Table 5. Summary of DTA and subgroup analysis of the included studies for the diagnosis of CAG.

\begin{tabular}{|c|c|c|c|c|c|c|c|}
\hline Subgroup & $\begin{array}{l}\text { Number of } \\
\text { Included } \\
\text { Studies }\end{array}$ & $\begin{array}{c}\text { Sensitivity } \\
(95 \% \mathrm{CI})\end{array}$ & $\begin{array}{l}\text { Specificity } \\
(95 \% \text { CI) }\end{array}$ & PLR & NLR & DOR & AUC \\
\hline Cut-off value: PG I $\leq 70 \mathrm{ng} / \mathrm{mL}$ and PG I/PG II ratio $\leq 3$ & 8 & $0.59(0.38-0.78)$ & $0.89(0.70-0.97)$ & $5.5(2.3-13.0)$ & $0.46(0.30-0.69)$ & $12(6-25)$ & $0.81(0.77-0.84)$ \\
\hline \multicolumn{8}{|l|}{ Age (years, median or mean) } \\
\hline$<60$ & 6 & $0.54(0.29-0.78)$ & $0.84(0.64-0.94)$ & $3.5(2.1-5.8)$ & $0.54(0.35-0.84)$ & $6(4-10)$ & $0.78(0.74-0.81)$ \\
\hline $60 \leq$ & 2 & Null & Null & Null & Null & Null & Null \\
\hline \multicolumn{8}{|l|}{ Methodological quality of included studies } \\
\hline High-quality & 5 & $0.68(0.54-0.79)$ & $0.76(0.64-0.85)$ & $2.79(2.04-3.80)$ & $0.43(0.32-0.57)$ & $7(4-10)$ & $0.78(0.74-0.82)$ \\
\hline Low-quality & 3 & Null & Null & Null & Null & Null & Null \\
\hline Cut-off value: PG I/PG II ratio $\leq 3$ & 8 & $0.50(0.28-0.72)$ & $0.94(0.82-0.98)$ & $7.8(3.3-18.1)$ & $0.53(0.34-0.82)$ & $15(6-37)$ & $0.85(0.81-0.88)$ \\
\hline \multicolumn{8}{|l|}{ Ethnicity } \\
\hline Western & 5 & $0.66(0.45-0.81)$ & $0.92(0.81-0.97)$ & $8.5(3.7-19.4)$ & $0.37(0.22-0.62)$ & $23(9-57)$ & $0.88(0.85-0.91)$ \\
\hline Asian & 3 & Null & Null & Null & Null & Null & Null \\
\hline \multicolumn{8}{|l|}{ Age (years, median or mean) } \\
\hline$<60$ & 5 & $0.31(0.15-0.53)$ & $0.97(0.80-0.99)$ & $8.9(2.2-35.9)$ & $0.71(0.57-0.89)$ & $12(3-45)$ & $0.67(0.62-0.71)$ \\
\hline $60 \leq$ & 3 & Null & Null & Null & Null & Null & Null \\
\hline \multicolumn{8}{|l|}{ Methodological quality of included studies } \\
\hline High-quality & 4 & $0.66(0.40-0.85)$ & $0.94(0.84-0.98)$ & $10.7(4.8-24.1)$ & $0.36(0.18-0.71)$ & $30(11-78)$ & $0.92(0.90-0.94)$ \\
\hline Low-quality & 4 & $0.32(0.12-0.62)$ & $0.92(0.63-0.99)$ & $4.1(1.4-12.3)$ & $0.73(0.56-0.97)$ & $6(2-15)$ & $0.67(0.63-0.71)$ \\
\hline \multicolumn{8}{|l|}{ Total number of included patients } \\
\hline$<1000$ & 7 & $0.49(0.24-0.74)$ & $0.95(0.87-0.98)$ & $9.6(4.8-19.4)$ & $0.54(0.33-0.89)$ & $18(8-41)$ & $0.90(0.87-0.92)$ \\
\hline $1000 \leq$ & 1 & Null & Null & Null & Null & Null & Null \\
\hline
\end{tabular}

Subgroups with less than four studies were defined as null because quantitative analysis was not possible. DTA, diagnostic test accuracy; CAG, chronic atrophic gastritis; CI, confidence interval; PLR, positive likelihood ratio; NLR, negative likelihood ratio; DOR, diagnostic odds ratio; AUC, area under the curve; PG, pepsinogen. Bold: Summary DTA of the included studies for the diagnosis of CAG. 

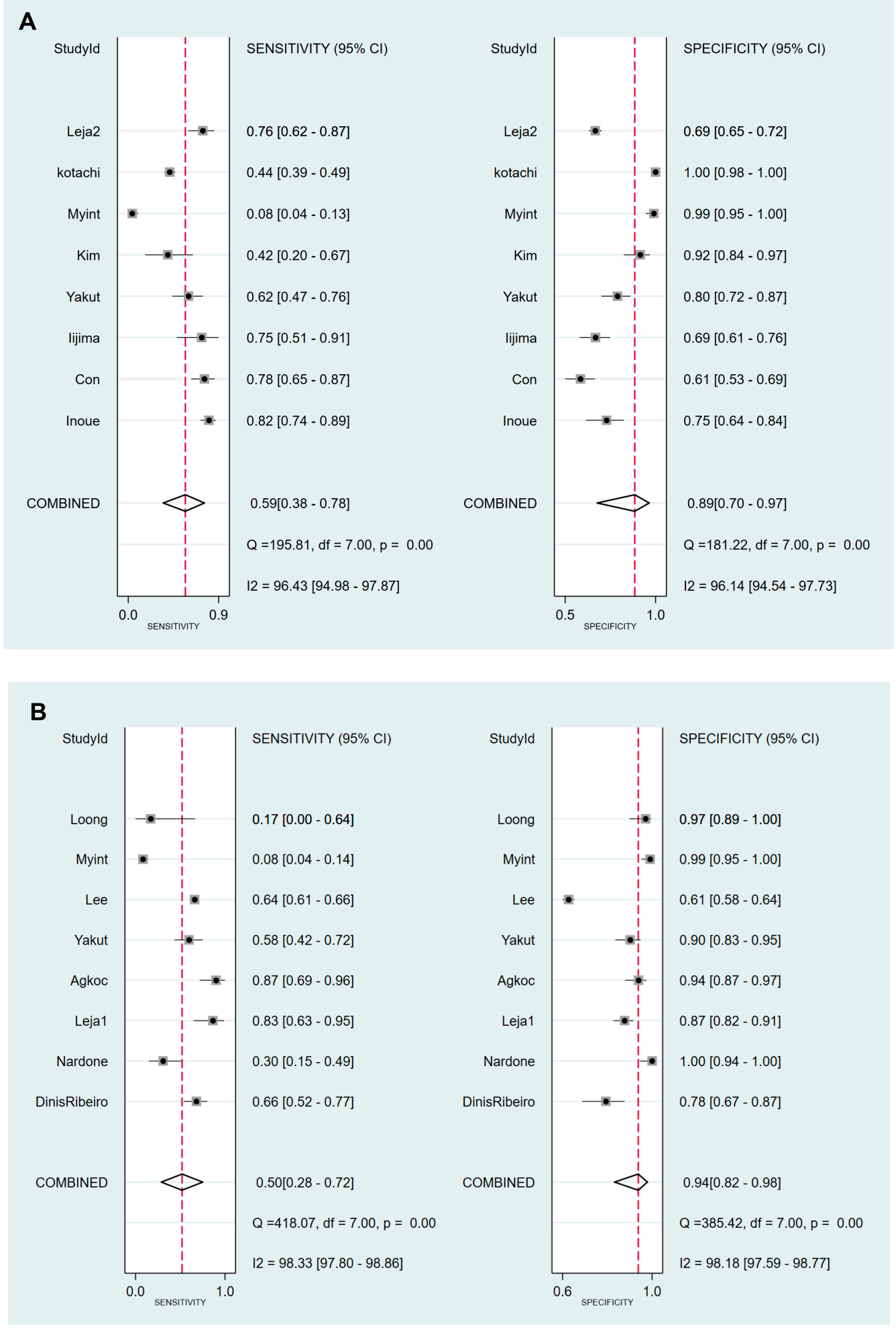

Figure 4. Forest plots of sensitivity and specificity for the diagnosis of CAG. (A) cut-off value with PG I $\leq 70 \mathrm{ng} / \mathrm{mL}$ and PG I/PG II ratio $\leq 3$, (B) cut-off value with PG I/PG II ratio $\leq 3$. CAG, chronic atrophic gastritis; PG, pepsinogen. 

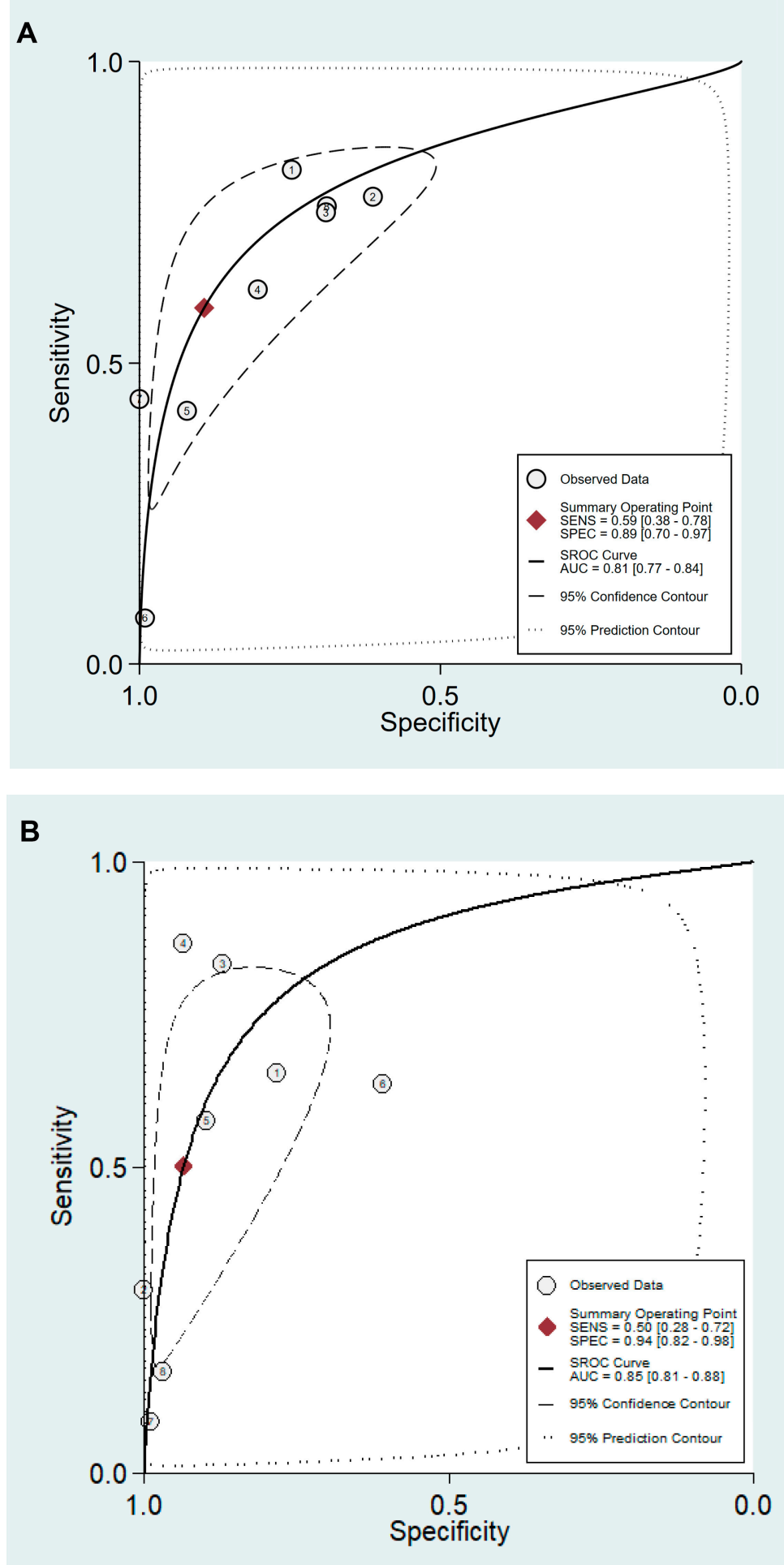

Figure 5. SROC curve with $95 \%$ confidence region and prediction region for the diagnosis of CAG. (A) cut-off value with PG I $\leq 70 \mathrm{ng} / \mathrm{mL}$ and PG I/PG II ratio $\leq 3$, (B) cut-off value with PG I/PG II ratio $\leq 3$. SROC, summary receiver operating characteristic; CAG, chronic atrophic gastritis; PG, pepsinogen; SENS, sensitivity; SPEC, specificity; AUC, area under the curve. 


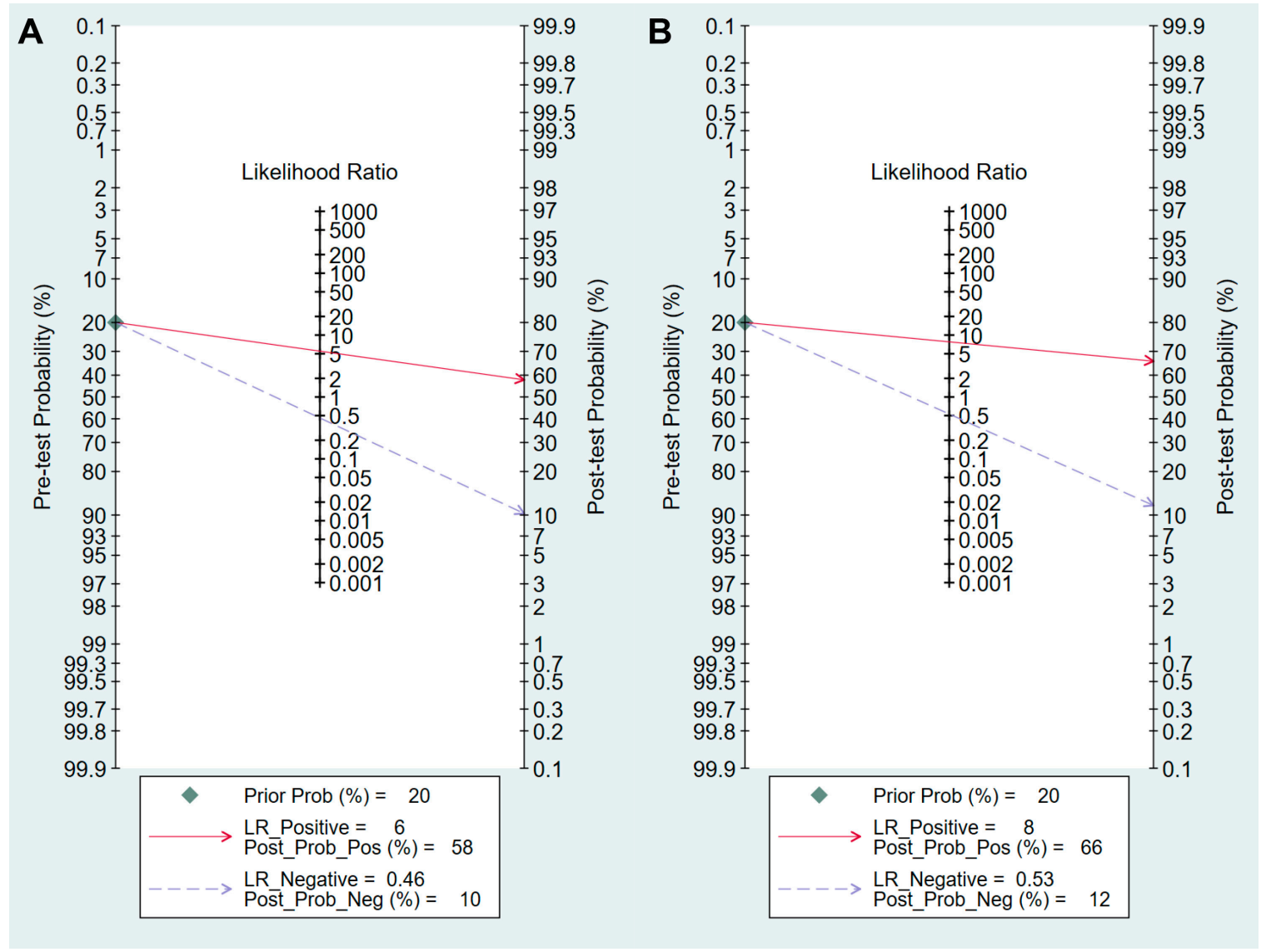

Figure 6. Fagan's normogram for the diagnosis of CAG. (A) cut-off value with PG I $\leq 70 \mathrm{ng} / \mathrm{mL}$ and PG I/PG II ratio $\leq 3$, (B) cut-off value with PG I/PG II ratio $\leq 3$. CAG, chronic atrophic gastritis; PG, pepsinogen; LR, likelihood raio.

Values of sensitivity, specificity, PLR, NLR, DOR, and AUC with 95\% CI for the cut-off value of PG I/PG II ratio $\leq 3$ for CAG diagnosis were 0.50 (0.28-0.72), 0.94 (0.82-0.98), 7.8 (3.3-18.1), 0.53 (0.34-0.82), 15 (6-37), and 0.85 (0.81-0.88), respectively (Table 5, Figure 4B). The SROC curve with $95 \%$ confidence region and prediction region is illustrated in Figure 5B. Fagan's nomogram shows that the posterior probability of CAG is $66 \%$ if patients are diagnosed as positive, and the posterior probability of CAG is $12 \%$ if patients are diagnosed as negative according to the sPGA with the cut-off value of PG I/PG II ratio $\leq 3$ (Figure 6B).

\subsection{DTA of sPGA in GC}

Since the minimum number of studies required for the quantitative analysis is four, DTA summary of sPGA in dysplasia or neoplasm was not calculated with a specific cut-off standard (only two or three studies were included with a specific cut-off value) (Figure 1).

Sensitivity, specificity, PLR, NLR, DOR and AUC with 95\% CI for the cut-off value of PG I $\leq 70$ $\mathrm{ng} / \mathrm{mL}$ and PG I/PG II ratio $\leq 3$ for GC diagnosis were 0.59 (0.50-0.67), $0.73(0.64-0.81), 2.2$ (1.7-2.9), 0.56 (0.46-0.68), 4 (3-6), and $0.70(0.66-0.74)$, respectively (Table 6, Figure 7A). The SROC curve with 95\% confidence region and prediction region is illustrated in Figure 8A. Assuming 20\% prevalence of GC (prior probability), Fagan's nomogram shows that the posterior probability of GC is $36 \%$ if patients are diagnosed as positive, and the posterior probability of GC is $13 \%$ if patients are diagnosed as negative according to the sPGA with the cut-off value of PG I $\leq 70 \mathrm{ng} / \mathrm{mL}$ and PG I/PG II ratio $\leq 3$ (Figure 9A). 
Table 6. Summary of DTA and subgroup analysis of the included studies for the diagnosis of GC.

\begin{tabular}{|c|c|c|c|c|c|c|c|}
\hline Subgroup & $\begin{array}{l}\text { Number of } \\
\text { Included } \\
\text { Studies }\end{array}$ & $\begin{array}{l}\text { Sensitivity } \\
(95 \% \mathrm{CI})\end{array}$ & $\begin{array}{c}\text { Specificity } \\
(95 \% \text { CI) }\end{array}$ & PLR & NLR & DOR & AUC \\
\hline Cut-off value: PG I $\leq 70 \mathrm{ng} / \mathrm{mL}$ and PG I/PG II ratio $\leq 3$ & 27 & $0.59(0.50-0.67)$ & $0.73(0.64-0.81)$ & $2.2(1.7-2.9)$ & $0.56(0.46-0.68)$ & $4(3-6)$ & $0.70(0.66-0.74)$ \\
\hline \multicolumn{8}{|l|}{ Ethnicity } \\
\hline Asian & 24 & $0.60(0.52-0.68)$ & $0.75(0.68-0.80)$ & $2.4(2.0-2.8)$ & $0.53(0.46-0.61)$ & $5(4-6)$ & $0.73(0.69-0.77)$ \\
\hline Western & 3 & null & null & null & null & null & null \\
\hline \multicolumn{8}{|l|}{ Published year } \\
\hline $2010-2018$ & 15 & $0.46(0.35-0.57)$ & $0.77(0.63-0.87)$ & $2.0(1.2-3.4)$ & $0.70(0.56-0.89)$ & $3(1-6)$ & $0.61(0.57-0.66)$ \\
\hline 1995-2009 & 12 & $0.71(0.64-0.78)$ & $0.68(0.59-0.76)$ & $2.2(1.8-2.8)$ & $0.42(0.34-0.52)$ & $5(4-8)$ & $0.76(0.72-0.79)$ \\
\hline \multicolumn{8}{|l|}{ Total number of included patients } \\
\hline$<1000$ & 9 & $0.50(0.34-0.65)$ & $0.65(0.44-0.81)$ & $1.4(0.7-2.8)$ & $0.78(0.48-1.25)$ & $2(1-6)$ & $0.58(0.54-0.62)$ \\
\hline $1000 \leq$ & 18 & $0.61(0.50-0.70)$ & $0.77(0.68-0.83)$ & $2.6(2.1-3.2)$ & $0.51(0.43-0.61)$ & $5(4-7)$ & $0.74(0.70-0.78)$ \\
\hline Cut-off value: $\mathrm{PG}$ I $\leq 70 \mathrm{ng} / \mathrm{mL}$ & 6 & $0.62(0.38-0.82)$ & $0.57(0.32-0.79)$ & $1.4(0.9-2.3)$ & $0.67(0.40-1.11)$ & $2(1-5)$ & $0.63(0.58-0.67)$ \\
\hline \multicolumn{8}{|l|}{ Methodological quality of included studies } \\
\hline High-quality & 5 & $0.52(0.33-0.70)$ & $0.66(0.43-0.83)$ & $1.5(0.8-2.9)$ & $0.73(0.47-1.16)$ & $2(1-6)$ & $0.61(0.57-0.65)$ \\
\hline Low-quality & 1 & null & null & null & null & null & null \\
\hline Cut-off value: PG I/PG II ratio $\leq 3$ & 11 & $0.56(0.35-0.75)$ & $0.78(0.62-0.88)$ & $2.5(1.7-3.7)$ & $0.56(0.39-0.81)$ & $4(3-8)$ & $0.74(0.70-0.78)$ \\
\hline \multicolumn{8}{|l|}{ Ethnicity } \\
\hline Asian & 10 & $0.52(0.30-0.73)$ & $0.75(0.58-0.87)$ & $2.1(1.7-2.7)$ & $0.63(0.47-0.86)$ & $3(2-5)$ & $0.70(0.66-0.74)$ \\
\hline Western & 1 & null & null & null & null & null & null \\
\hline
\end{tabular}

Subgroups with less than four studies were defined as null because quantitative analysis was not possible. DTA, diagnostic test accuracy; GC, gastric cancer; CI, confidence interval; PLR, positive likelihood ratio; NLR, negative likelihood ratio; DOR, diagnostic odds ratio; AUC, area under the curve; PG, pepsinogen. Bold: Summary DTA of the included studies for the diagnosis of GC. 


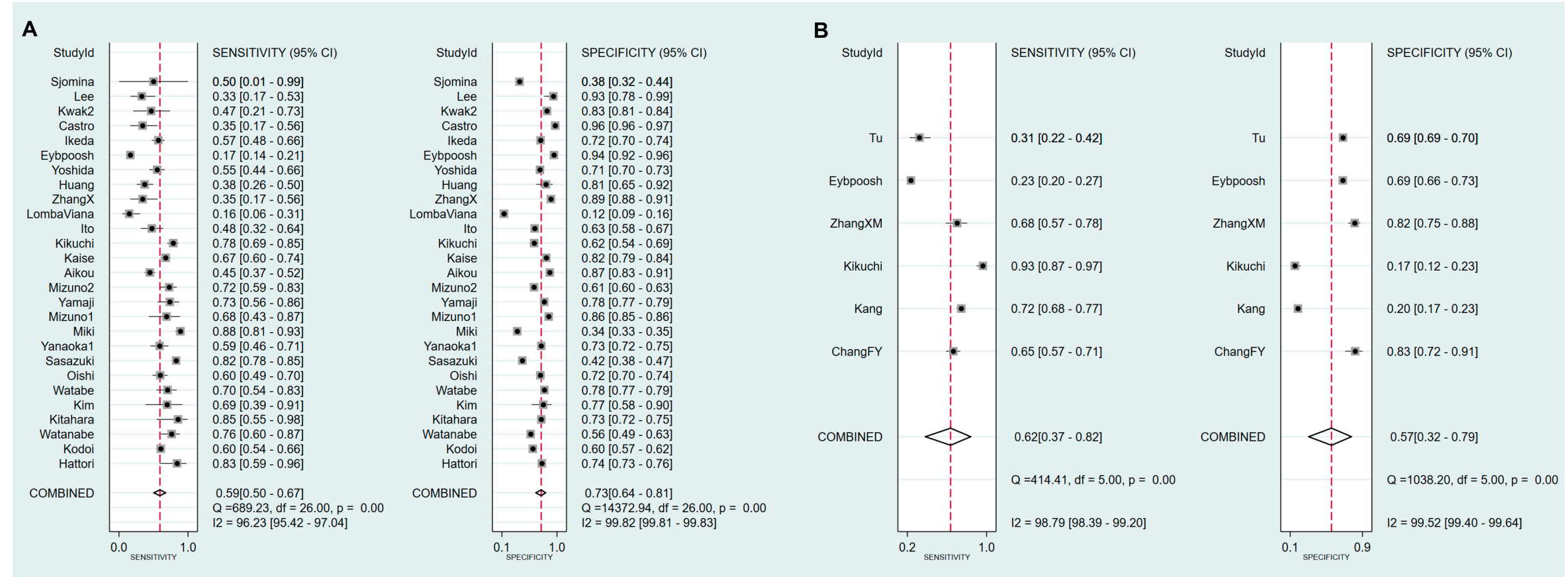

Figure 7. Cont. 


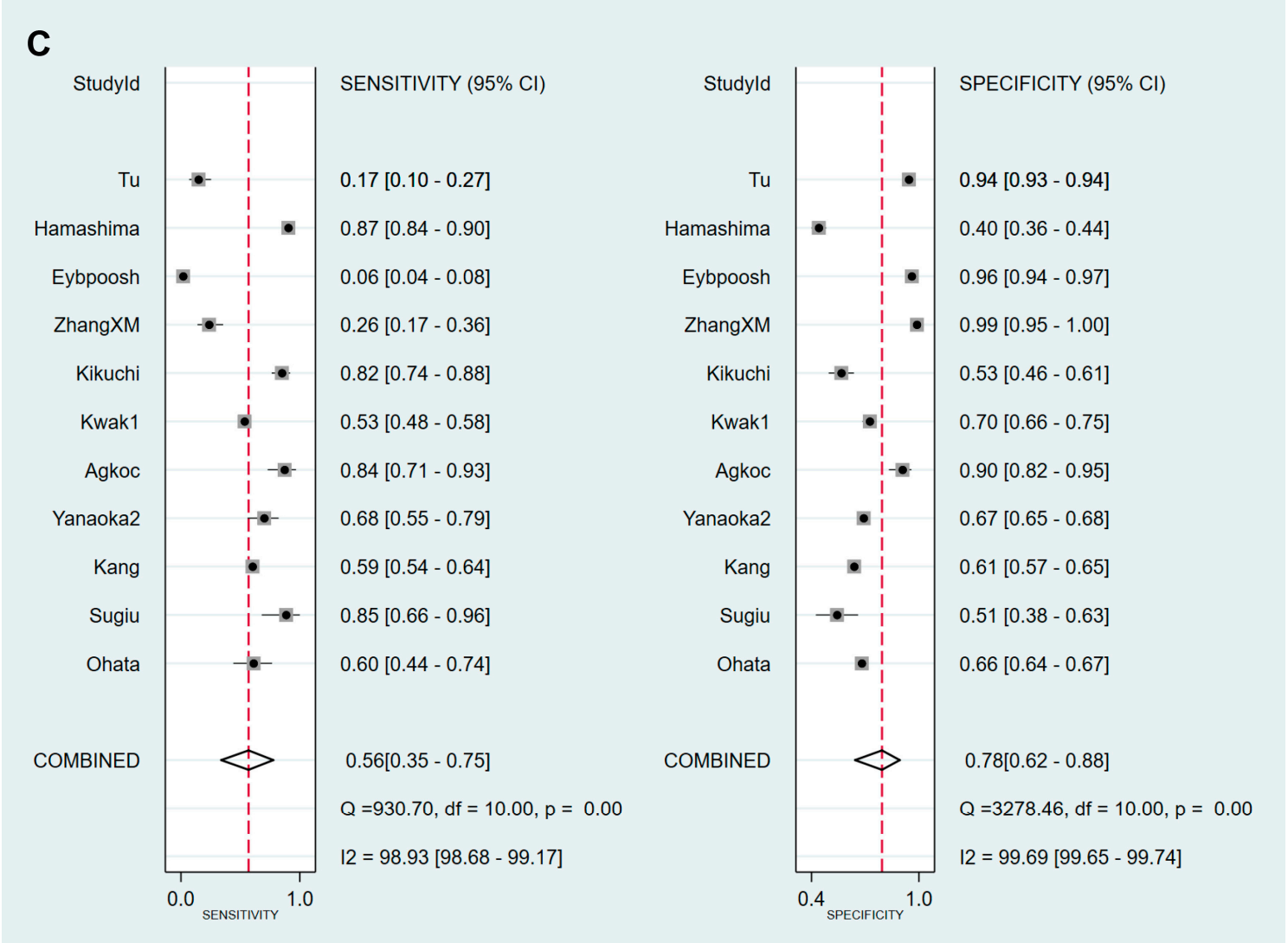

Figure 7. Forest plots of sensitivity and specificity for the diagnosis of GC. (A) cut-off value with PG I $\leq 70 \mathrm{ng} / \mathrm{mL}$ and PG I/PG II ratio $\leq 3$, (B) cut-off value with PG I $\leq 70 \mathrm{ng} / \mathrm{mL},(\mathbf{C})$ cut-off value with PG I/PG II ratio $\leq 3$. GC, gastric cancer; PG, pepsinogen. 

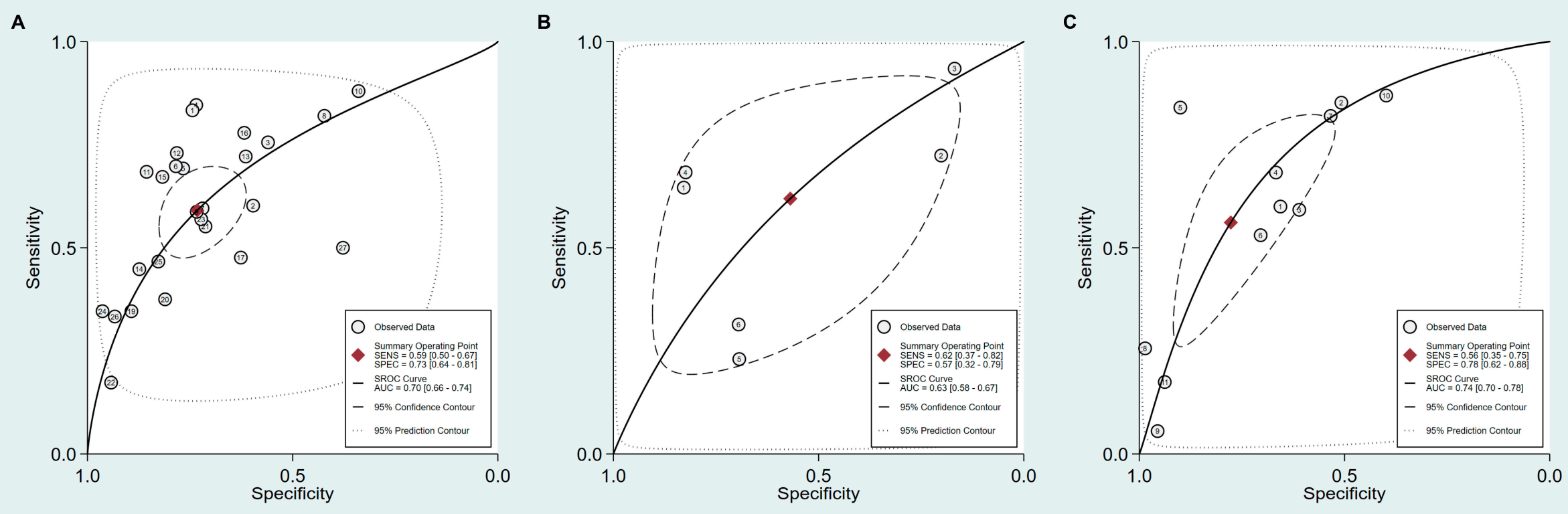

Figure 8. SROC curve with $95 \%$ confidence region and prediction region for the diagnosis of GC. (A) cut-off value with PG I $\leq 70 \mathrm{ng} / \mathrm{mL}$ and PG I/PG II ratio $\leq 3$, (B) cut-off value with PG I $\leq 70 \mathrm{ng} / \mathrm{mL}$, (C) cut-off value with PG I/PG II ratio $\leq 3$. SROC, summary receiver operating characteristic; GC, gastric cancer; PG, pepsinogen. 


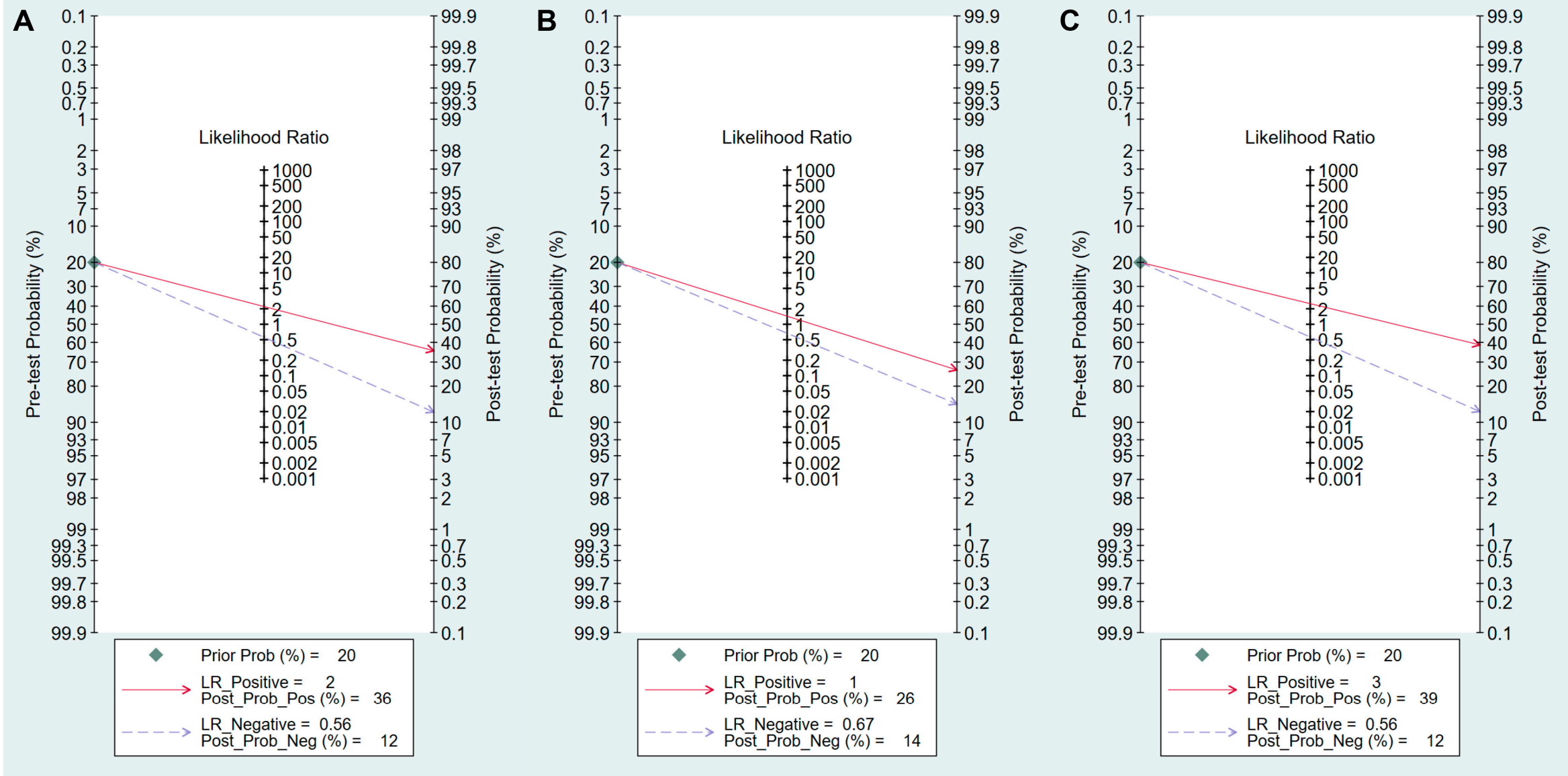

Figure 9. Fagan's normogram for the diagnosis of GC. (A) cut-off value with PG I $\leq 70 \mathrm{ng} / \mathrm{mL}$ and PG I/PG II ratio $\leq 3$, (B) cut-off value with PG I $\leq 70 \mathrm{ng} / \mathrm{mL}$, (C) cut-off value with PG I/PG II ratio $\leq 3$. GC, gastric cancer; PG, pepsinogen; LR, likelihood raio. 
Values for sensitivity, specificity, PLR, NLR, DOR, and AUC with 95\% CI for the cut-off value of PG I $\leq 70 \mathrm{ng} / \mathrm{mL}$ for GC diagnosis were 0.62 (0.38-0.82), 0.57 (0.32-0.79), 1.4 (0.9-2.3), 0.67 (0.40-1.11), 2 (1-5), and $0.63(0.58-0.67)$, respectively (Table 6, Figure 7B). The SROC curve with $95 \%$ confidence region and prediction region is illustrated in Figure 8B. Fagan's nomogram shows that the posterior probability of GC is $26 \%$ if patients are diagnosed as positive, and the posterior probability of GC is $14 \%$ if patients are diagnosed as negative according to the sPGA with the cut-off value of PG I $\leq 70 \mathrm{ng} / \mathrm{mL}$ (Figure 9B).

Values for sensitivity, specificity, PLR, NLR, DOR, and AUC with 95\% CI for the cut-off value of PG I/PG II ratio $\leq 3$ for GC diagnosis were 0.56 (0.35-0.75), 0.78 (0.62-0.88), 2.5 (1.7-3.7), 0.56 (0.39-0.81), 4 (3-8), and 0.74 (0.70-0.78), respectively (Table 6, Figure 7C). The SROC curve with 95\% confidence region and prediction region is illustrated in Figure 8C. Fagan's normogram shows that the posterior probability of GC is $39 \%$ if patients are diagnosed as positive, and the posterior probability of GC is $12 \%$ if patients are diagnosed as negative according to the sPGA with the cut-off value of PG I/PG II ratio $\leq 3$ (Figure 9C).

\subsection{Exploring Heterogeneity with Meta-Regression and Subgroup Analysis of sPGA in CAG}

For the diagnosis of CAG with the cut-off value of PG I $\leq 70 \mathrm{ng} / \mathrm{mL}$ and PG $\mathrm{I} / \mathrm{PG}$ II ratio $\leq 3$, the SROC curve was symmetric (Figure 5A). We observed a negative correlation coefficient between logit transformed sensitivity and specificity $(-0.92)$ and asymmetry parameter, $\beta$, with non-significant $p$ value $(p=0.14)$ indicating no heterogeneity among studies. However, $95 \%$ prediction region in the SROC curve was wide, and age $(p=0.01)$ and methodological quality of the included studies $(p=0.01)$ were found to be the source of heterogeneity in meta-regression. Subgroup analyses according to the modifiers of heterogeneity showed lower AUCs in studies with a younger population ( $<60$ years) and high methodological quality (Table 5).

For the diagnosis of CAG with the cut-off value of PG I/PG II ratio $\leq 3$, the SROC curve was symmetric (Figure 5B). We observed a negative correlation coefficient between logit transformed sensitivity and specificity (-0.72) and asymmetry parameter, $\beta$, with non-significant $p$ value $(p=0.70)$, indicating no heterogeneity among studies. However, the $95 \%$ prediction region in the SROC curve was wide, and ethnicity $(p=0.02)$, age $(p=0.03)$, methodological quality of included studies $(p=0.01)$, and total number of patients $(p=0.05)$ were found to be the source of heterogeneity in meta-regression. Subgroup analyses according to the modifiers of heterogeneity showed lower AUCs in studies with a younger population (<60 years), an Asian population, low methodological quality, and higher number of included patients $(\geq 1000)$ (Table 5$)$.

\subsection{Exploring Heterogeneity with Meta-Regression and Subgroup Analysis of sPGA in GC}

For the diagnosis of GC with the cut-off value of PG I $\leq 70 \mathrm{ng} / \mathrm{mL}$ and PG I/PG II ratio $\leq 3$, SROC curve was symmetric (Figure 8A). We observed a negative correlation coefficient between logit transformed sensitivity and specificity $(-0.38)$ and asymmetry parameter, $\beta$, with non-significant $p$ value $(p=0.26)$, indicating no heterogeneity among studies. However, $95 \%$ prediction region in SROC curve was wide and ethnicity $(p=0.02)$, published year $(p=0.01)$, and total number of patients $(p=0.01)$ were found to be the source of heterogeneity in meta-regression. Subgroup analyses according to the modifiers of heterogeneity showed lower AUCs in studies with Western population, more recent publications (2010-2018 vs. 1995-2009) and lower number of included patients (<1000) (Table 6).

For the diagnosis of GC with the cut-off value of PG I $\leq 70 \mathrm{ng} / \mathrm{mL}$, the SROC curve was symmetric (Figure 8B). We observed a negative correlation coefficient between logit transformed sensitivity and specificity $(-0.61)$ and asymmetry parameter, $\beta$, with non-significant $p$ value $(p=0.92)$, indicating no heterogeneity among studies. However, $95 \%$ prediction region in the SROC curve was wide and methodological quality of included studies $(p=0.05)$, detection method of sPGA $(p<0.01)$, and total number of patients $(p<0.01)$ were found to be the source of heterogeneity in meta-regression. Subgroup analyses according to the modifiers of heterogeneity was only possible for methodological quality, because the number of subgroups classified according to the other modifiers was lower than four. Subgroup analysis showed lower AUCs in studies with high methodological quality (Table 6). 
For the diagnosis of GC with the cut-off value of PG I/PG II ratio $\leq 3$, the SROC curve was symmetric (Figure $8 \mathrm{C}$ ). We observed a negative correlation coefficient between logit transformed sensitivity and specificity $(-0.83)$ and asymmetry parameter, $\beta$, with non-significant $p$ value $(p=0.57)$, indicating no heterogeneity among studies. Only ethnicity $(p<0.01)$ was found to be the source of heterogeneity in meta-regression. Subgroup analyses according to the modifier of heterogeneity showed lower AUCs in studies with Asian populations (Table 6).

\subsection{Publication Bias}

Publication bias was not evaluated for diagnosis of CAG, as fewer than 10 studies on this subject were included with any cut-off values.

For the diagnosis of GC, 27 studies were included with cut-off value of PG I $\leq 70 \mathrm{ng} / \mathrm{mL}$ and PG I/PG II ratio $\leq 3$. Deeks' funnel plot asymmetry test showed no evidence of publication bias $(p=0.71)$ (Figure 10A). Publication bias was not evaluated for cut-off of PG I $\leq 70 \mathrm{ng} / \mathrm{mL}$, as only six studies were included with this cut-off value. Eleven studies were included with cut-off of PG I/PG II ratio $\leq 3$. Although Deeks' funnel plot asymmetry test for 11 studies with a cut-off value of PG I/PG II ratio $\leq 3$ showed a $p$ value of 0.02 , indicating publication bias, the plot was symmetrical with respect to the regression line (Figure 10B).

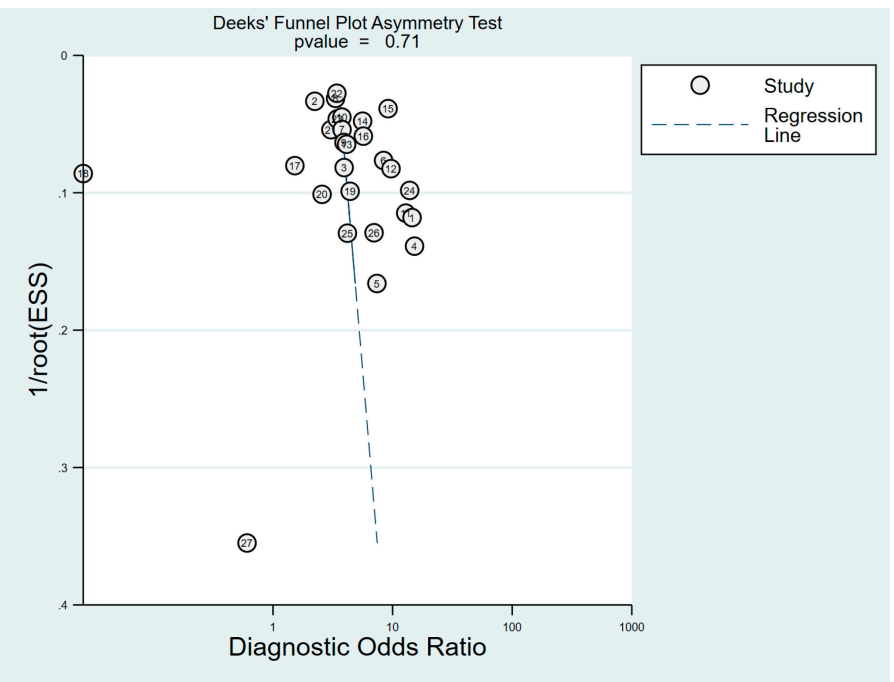

(A)

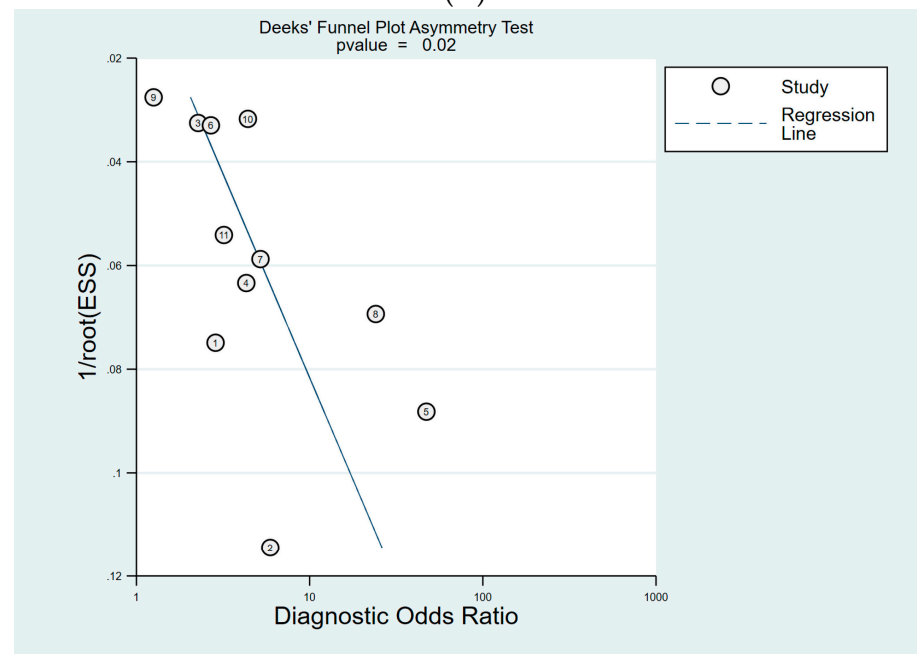

(B)

Figure 10. Deek's funnel plot for the diagnosis of GC. (A) cut-off value with PG I $\leq 70 \mathrm{ng} / \mathrm{mL}$ and PG I/PG II ratio $\leq 3$, (B) cut-off value with PG I/PG II ratio $\leq 3$. GC, gastric cancer; PG, pepsinogen. 


\section{Discussion}

There are two main types of pepsinogen (PG), namely PG I and PG II, which are proenzymes of pepsin, an endoproteinase present in the gastric juice [21]. PG I is secreted mainly by chief cells in the fundic glands of the stomach fundus and body, whereas PG II is secreted by all the gastric glands and the proximal duodenal mucosa (Brunner's glands) $[5,21,74,75]$. The secretion ability of gastric mucosa is usually intact in the case of no infection or acute H. pylori infection [75]. However, when chronic H. pylori infection with CAG extends from antrum to corpus of stomach, chief cells are replaced by pyloric glands [7]. Therefore, concentration of serum PG I decreases due to the damaged secretion ability of gastric mucosa, whereas the concentration of PG II remains relatively intact, leading to a low PG I/PG II ratio and this value reflects the severity of CAG $[4,7,75]$.

Although various cut-off values have been suggested, PG I $\leq 70 \mathrm{ng} / \mathrm{mL}$ and PG I/PG II ratio $\leq 3$ have been proposed for the prediction of CAG or GC $[4,8]$. However, previous meta-analyses presented only pooled outcomes, which cannot determine the diagnostic validity of sPGA with cut-off value of PG I $\leq 70 \mathrm{ng} / \mathrm{mL}$ and PG I/PG II ratio $\leq 3$ [9,10], although no threshold effect was detected [9]. Moreover, the meta-analysis determined publication bias with Begg's test, which is inappropriate for DTA because of type I error inflation [9]. Serum concentration of gastrin, which is produced and secreted primarily by the $G$ cells in antrum, is increased when the corpus mucosa is predominantly involved, and decreased with antral predominant gastric atrophy $[5,75]$. Combined efficacy of sPGA with $H$. pylori antibody [11] and/or gastrin-17 [12,13] has been indicated for the prediction of gastric cancer [11] and CAG [12,13], and it is mainly used in Europe (as panel test). However, sPGA is preferable to serum gastrin measurement because sPGA reflects gastric mucosal status better [75]. Moreover, previous meta-analyses could not determine the diagnostic validity of sPGA alone [11-13]. Although previous meta-analyses, published in 2004 and 2006, reported diagnostic validity of sPGA with cut-off value of PG I $\leq 70 \mathrm{ng} / \mathrm{mL}$ and PG I/PG II ratio $\leq 3$, these studies cannot reflect recently published data and had several methodological pitfalls $[8,14]$ (Table 1).

The results of our study confirm that the performance of sPGA is better for the diagnosis of CAG than GC, and sPGA has potential for CAG or GC screening (triage test) considering its high specificity (Tables 5 and 6). Another finding of this study is the diagnostic validity of sPGA with cut-off value of PG I/PG II ratio $\leq 3$. Although direct comparison of DOR does not have significant implications, the DTA of sPGA with cut-off value of PG I/PG II ratio $\leq 3$ was similar to that with cut-off value of PG I $\leq 70 \mathrm{ng} / \mathrm{mL}$ and PG I/PG II ratio $\leq 3$ (Tables 5 and 6 ). A recent study also indicated that the PG I/PG II ratio is one of the stomach-specific circulating biomarkers for GC risk assessment [69]. It is also known that sPGA is a cost-effective diagnostic test and useful to reduce the intestinal-type GC, especially for high-risk populations $[76,77]$. Considering the non-invasiveness and easily interpretable characteristics, the results of this study indicates the utility of sPGA as a population-based screening tool for CAG or GC.

Compared to the previous meta-analyses that combined the diagnostic values with various cut-off standards in a single outcome, the results of this study showed slightly lower diagnostic values (AUC for the diagnosis of CAG: 0.81 vs. $0.85 /$ AUC for the diagnosis of GC: 0.70 vs. $0.76 /$ DOR for the diagnosis of GC: 4 vs. 5.41), indicating overestimation of diagnostic validity in previous studies $[9,10]$.

In terms of the reasons of heterogeneity, subgroup analyses showed decreased $I^{2}$ values in high-quality studies with cut-off value of PG I $\leq 70 \mathrm{ng} / \mathrm{mL}$ and PG I/PG II ratio $\leq 3$ for the diagnosis of CAG compared to those of main analysis ( $I^{2}$ of sensitivity: $96.4 \%$ to $61.5 \%, I^{2}$ of specificity: $96.1 \%$ to $88.6 \%$ ) (Figure 4 and Table 5). In the subgroup analyses with a cut-off value of PG I/PG II ratio $\leq 3$ for the diagnosis of CAG, high-quality studies ( $I^{2}$ of sensitivity: $98.3 \%$ to $88.5 \%, I^{2}$ of specificity: $98.2 \%$ to $74.2 \%$ ) and a Western population ( $I^{2}$ of sensitivity: $98.3 \%$ to $85.1 \%, I^{2}$ of specificity: $98.2 \%$ to $80 \%$ ) also showed decreased $I^{2}$ values compared to those of main analysis, indicating needs for high-quality studies with a Western population to enhance the evidence level in this topic. Although studies with Western population showed slightly higher AUC $(0.88$ vs. 0.85$)$ than pooled AUC, the value is closer to that of high-quality studies subgroup (0.92), indicating it is not an overestimation, rather we need more 
Western population data to enhance the level of evidence. In Table 6, recently published subgroup showed much lower AUC (0.61 vs. 0.76) than that of old publications; however, the AUC of recently published subgroup was closer to that of high-quality subgroup ( 0.68 ; data not shown because it was not a source of heterogeneity in meta-regression), indicating overestimation of older publications. There was a change in diagnostic values according to the modifiers in the subgroup analyses for the diagnosis of GC; however, such decrease of $I^{2}$ values in the subgroup analyses was not detected (Table 6) (data about $I^{2}$ not shown in the results section).

The distribution of CAG or IM (known as pre-malignant or high-risk lesions of GC) in entire population affects the determination of optimal cut-off value of sPGA (spectrum bias). In our meta-analysis, a study by Dinis-Ribeiro et al. [21] included high-risk patients of GC, such as those with AG, IM, or dysplasia, excluding the healthy population, and showed higher sensitivity compared to that of pooled analysis with cut-off of PG I/PG II ratio $\leq 3$ (0.66 vs. 0.50 ) (Table 5). A previous study by Valli De Re et al. [78] also included high-risk patients, such as first-degree relatives of patients with GC or CAG, and showed high sensitivity and specificity of 0.96 and 0.93 for the prediction of Operative Link on Gastric Intestinal Metaplasia Assessment (OLGIM) stage $\geq 2$ with cut-off of PG I $\leq 47.9 \mathrm{ng} / \mathrm{mL}$. The proposed cut-off of PG I was lower than $70 \mathrm{ng} / \mathrm{mL}$ because they included a high-risk population. However, they proposed algorithm approach of using gastrin-17 first, because they included high-risk patients and gastrin-17 showed highest discrimination capacity of CAG among proposed biomarkers. For the next-step, they recommended using PG I $\leq 47.9 \mathrm{ng} / \mathrm{mL}$ for the prediction of OLGIM stage $\geq 2$. PG I generally shows a low level in CAG; however, if an optimal cut-off should be determined in a high-risk population, lower cut-off value might be required. A combination with a marker, such as gastrin-17, which shows high discriminative performance of CAG, could be considered.

The present study rigorously investigated the diagnostic validity of sPGA with well-known cut-off value of PG I $\leq 70 \mathrm{ng} / \mathrm{mL}$ and/or PG I/PG II ratio $\leq 3$ for the diagnosis of CAG or GC, excluding threshold effect. However, the study has several limitations. Firstly, a relatively small number of studies were enrolled with cut-off value of PG I $\leq 70 \mathrm{ng} / \mathrm{mL}$ or PG I/PG II ratio $\leq 3$ compared to the combination of both values. Secondly, potential publication bias was suspected in the diagnosis of GC with cut-off value of PG I/PG II ratio $\leq 3$ (Deeks' funnel plot asymmetry test showed $p$ value of 0.02 , although the plot showed symmetrical shape), probably due to relatively small number of enrolled studies ( $n=11)$ (Figure 10B). Thirdly, substantial heterogeneity among studies were suspected, although rigorous subgroup analyses were performed and interpreted. Fourthly, this meta-analysis included many case-control studies, which easily overestimate the diagnostic validity of the index test. Fifthly, the diagnostic validity of sPGA is known to be associated with the smoking, $H$. pylori infection status, or the proportion of diffuse-type GC of the enrolled population [79]. However, this information was presented only in small portion of enrolled studies, limiting further analysis.

In conclusion, sPGA has the potential for use as a CAG or GC screening (triage test). Considering the heterogeneity among studies found in this analysis, high-quality studies based on Western populations could enhance the evidence level in this topic. Most importantly, considering that the usefulness of sPGA may be different between countries, this biomarker should be validated before practically using it for the screening of CAG or GC, because the enrolled studies were conducted in only a few countries.

Author Contributions: Conceptualization, C.S.B.; Data curation, C.S.B., J.J.L., and G.H.B.; Formal analysis, C.S.B., J.J.L., and G.H.B.; Funding acquisition, C.S.B.; Investigation, C.S.B., J.J.L., and G.H.B.; Methodology, C.S.B.; Project administration, C.S.B.; Resources, C.S.B., J.J.L., and G.H.B.; Supervision, C.S.B.; Writing-original draft, C.S.B.; Writing-review and editing, C.S.B.

Funding: Funding for this research was provided by the Bio and Medical Technology Development Program of the National Research Foundation (NRF) and by the Korean government, Ministry of Science and ICT (MSIT) (grant number NRF2017M3A9E8033253).

Conflicts of Interest: The authors declare no conflict of interest.

Access to Data: All investigators will have access to the final dataset. All of the data is accessible and available upon request by corresponding author. 


\section{Abbreviations}

sPGA, serum pepsinogen assay; PG, pepsinogen; CAG, chronic atrophic gastritis; GC, gastric cancer; IM, intestinal metaplasia; DTA, diagnostic test accuracy; TP, true positive; FP, false positive; TN, true negative; FN, false negative; PPV, positive predictive value; NPV, negative predictive value; PLR, positive likelihood ratio; NLR, negative likelihood ratio; DOR, diagnostic odds ratio; QUADAS-2, Quality Assessment of Diagnostic Accuracy Studies-2; CI, confidence interval; HSROC, hierarchical summary receiver operating characteristic; ELISA, enzyme-linked immunosorbent assay; L-TIA, latex-enhanced turbidimetric immunoassay; RIA, radioimmunoassay; CLIA, chemiluminescent immunoassay; EIA, enzyme immunoassay; AUC, area under the curve.

\section{References}

1. World Health Organization (WHO). Available online: http://www.who.int/mediacentre/factsheets/fs297/en (accessed on 1 October 2018).

2. Correa, P. A human model of gastric carcinogenesis. Cancer Res. 1988, 48, 3554-3560.

3. De Vries, A.C.; van Grieken, N.C.; Looman, C.W.; Casparie, M.K.; de Vries, E.; Meijer, G.A.; Kuipers, E.J. Gastric cancer risk in patients with premalignant gastric lesions: A nationwide cohort study in the Netherlands. Gastroenterology 2008, 134, 945-952. [CrossRef]

4. Bang, C.S.; Lee, J.J.; Baik, G.H. Diagnostic performance of serum pepsinogen assay for the prediction of atrophic gastritis and gastric neoplasms: Protocol for a systematic review and meta-analysis. Medicine 2019, 98, e14240. [CrossRef] [PubMed]

5. Jencks, D.S.; Adam, J.D.; Borum, M.L.; Koh, J.M.; Stephen, S.; Doman, D.B. Overviewof current concepts in gastric intestinal metaplasia and gastric cancer. Gastroenterol. Hepatol. 2018, 14, 92-101.

6. Jun, J.K.; Choi, K.S.; Lee, H.Y.; Suh, M.; Park, B.; Song, S.H.; Jung, K.W.; Lee, C.W.; Choi, C.W.; Choi, I.J.; et al. Effectiveness of the Korean National CancerScreening program in reducing gastric cancer mortality. Gastroenterology 2017, 152, 1319-1328.e7. [CrossRef] [PubMed]

7. Park, Y.H.; Kim, N. Review of atrophic gastritis and intestinal metaplasia as a premalignant lesion of gastric cancer. J. Cancer Prev. 2015, 20, 25-40. [CrossRef] [PubMed]

8. Dinis-Ribeiro, M.; Yamaki, G.; Miki, K.; Costa-Pereira, A.; Matsukawa, M.; Kurihara, M. Meta-analysis on the validity of pepsinogen test for gastric carcinoma, dysplasia or chronic atrophic gastritis screening. J. Med. Screen. 2004, 11, 141-147. [CrossRef] [PubMed]

9. Huang, Y.K.; Yu, J.C.; Kang, W.M.; Ma, Z.Q.; Ye, X.; Tian, S.B.; Yan, C. Significance of Serum Pepsinogens as a Biomarker for Gastric Cancer and Atrophic Gastritis Screening: A Systematic Review and Meta-Analysis. PLOS ONE 2015, 10, e0142080. [CrossRef]

10. Liu, L.; Lang, J.; Jin, Y.; Chen, Y.; Chang, W.; Yao, Y.; Yu, J. The Value of Pepsinogen in GC Screening: A Systematic Review and Meta-Analysis. Gastroenterol. Res. Pract. 2019, 2019, 7087232. [CrossRef]

11. Terasawa, T.; Nishida, H.; Kato, K.; Miyashiro, I.; Yoshikawa, T.; Takaku, R.; Hamashima, C. Prediction of gastric cancer development by serum pepsinogen test and Helicobacter pylori seropositivity in Eastern Asians: A systematic review and meta-analysis. PLoS ONE 2014, 9, e109783. [CrossRef] [PubMed]

12. Zagari, R.M.; Rabitti, S.; Greenwood, D.C.; Eusebi, L.H.; Vestito, A.; Bazzoli, F. Systematic review with meta-analysis: Diagnostic performance of the combination of pepsinogen, gastrin-17 and anti-Helicobacter pylori antibodies serum assays for the diagnosis of atrophic gastritis. Aliment. Pharmacol. Ther. 2017, 46, 657-667. [CrossRef] [PubMed]

13. Syrjanen, K. A Panel of Serum Biomarkers (GastroPanel(R)) in Non-invasive Diagnosis of Atrophic Gastritis. Systematic Review and Meta-analysis. Anticancer Res. 2016, 36, 5133-5144. [CrossRef] [PubMed]

14. Miki, K. Gastric cancer screening using the serum pepsinogen test method. Gastric. Cancer 2006, 9, $245-253$. [CrossRef] [PubMed]

15. Shamseer, L.; Moher, D.; Clarke, M.; Ghersi, D.; Liberati, A.; Petticrew, P.; Stewart, L.A. Preferred reporting items for systematic review and meta-analysis protocols (PRISMA-P) 2015: Elaboration and explanation. BMJ 2015, 350, g7647. [CrossRef] [PubMed]

16. Whiting, P.F.; Rutjes, A.W.; Westwood, M.E.; Mallett, S.; Deeks, J.J.; Reitsma, J.B.; Leeflang, M.M.; Sterne, J.A. QUADAS-2: A revised tool for the quality assessment of diagnostic accuracy studies. Ann. Intern. Med. 2011, 155, 529-536. [CrossRef] [PubMed] 
17. Reitsma, J.B.; Glas, A.S.; Rutjes, A.W.; Scholten, R.J.; Bossuyt, P.M.; Zwinderman, A.H. Bivariate analysis of sensitivity and specificity produces informative summary measures in diagnostic reviews. J. Clin. Epidemiol. 2005, 58, 982-990. [CrossRef]

18. Rutter, C.M.; Gatsonis, C.A. A hierarchical regression approach to meta-analysis of diagnostic test accuracy evaluations. Stat. Med. 2001, 20, 2865-2884. [CrossRef]

19. Harbord, R.M.; Whiting, P. Metandi: Meta-analysis of diagnostic accuracy using hierarchical logistic regression. Stata J. 2009, 9, 211-229. [CrossRef]

20. Inoue, M.; Kobayashi, S.; Matsuura, A.; Hamajima, N.; Tajima, K.; Tominaga, S. Agreement of endoscopic findings and serum pepsinogen levels as an indicator of atrophic gastritis. Cancer Epidemiol. Biomark. Prev. 1998, 7, 261-263.

21. Dinis-Ribeiro, M.; Da Costa-Pereira, A.; Lopes, C.; Barbosa, J.; Guilherme, M.; Moreira-Dias, L.; Lomba-Viana, H.; Silva, R.; Abreu, N.; Lomba-Viana, R. Validity of serum pepsinogen I/II ratio for the diagnosis of gastric epithelial dysplasia and intestinal metaplasia during the follow-up of patients at risk for intestinal-type gastric adenocarcinoma. Neoplasia 2004, 6, 449-456. [CrossRef]

22. Nardone, G.; Rocco, A.; Staibano, S.; Mezza, E.; Autiero, G.; Compare, D.; De Rosa, G.; Budillon, G. Diagnostic accuracy of the serum profile of gastric mucosa in relation to histological and morphometric diagnosis of atrophy. Aliment. Pharmacol. Ther. 2005, 22, 1139-1146. [CrossRef]

23. Con, S.A.; Con-Wong, R.; Con-Chin, G.R.; Con-Chin, V.G.; Takeuchi, H.; Valerín, A.L.; Echandi, G.; Mena, F.; Brenes, F.; Yasuda, N.; et al. Serum pepsinogen levels, Helicobacter pylori CagA status, and cytokine gene polymorphisms associated with gastric premalignant lesions in Costa Rica. Cancer Epidemiol. Biomark. Prev. 2007, 16, 2631-2636. [CrossRef]

24. Iijima, K.; Abe, Y.; Kikuchi, R.; Koike, T.; Ohara, S.; Sipponen, P.; Shimosegawa, T. Serum biomarker tests are useful in delineating between patients with gastric atrophy and normal, healthy stomach. World J. Gastroenterol. 2009, 15, 853-859. [CrossRef]

25. Leja, M.; Kupcinskas, L.; Funka, K.; Sudraba, A.; Jonaitis, L.; Ivanauskas, A.; Janciauskas, D.; Kiudelis, G.; Chiu, H.M.; Lin, J.T. The Validity of a Biomarker Method for Indirect Detection of Gastric Mucosal Atrophy Versus Standard Histopathology. Dig. Dis. Sci. 2009, 54, 2377-2384. [CrossRef]

26. Agkoc, M.; Dursun, H.; Albayrak, F.; Yilmaz, O.; Kiziltunc, A.; Yilmaz, A.; Gundogdu, C. Usefulness of serum pepsinogen levels as a screening test for atrophic gastritis and gastric cancer. Eurasian. J. Med. 2010, 42, 15-18. [CrossRef]

27. Yakut, M.; Ormeci, N.; Erdal, H.; Keskin, O.; Karayel, Z.; Tutkak, H.; Soykan, I. The association between precancerous gastric lesions and serum pepsinogens,serum gastrin, vascular endothelial growth factor, serum interleukin-1 Beta, serum toll-like receptor-4 levels and Helicobacter pylori Cag A status. Clin. Res. Hepatol. Gastroenterol. 2013, 37, 302-311. [CrossRef]

28. Lee, J.Y.; Kim, N.; Lee, H.S.; Oh, J.C.; Kwon, Y.H.; Choi, Y.J.; Yoon, K.C.; Hwang, J.J.; Lee, H.J.; Lee, A.; et al. Correlations among endoscopic, histologic and serologic diagnoses for the assessment of atrophic gastritis. J. Cancer Prev. 2014, 19, 47-55. [CrossRef]

29. Kim, E.H.; Kang, H.; Park, C.H.; Choi, H.S.; Jung, D.H.; Chung, H.; Park, J.C.; Shin, S.K.; Lee, S.K.; Lee, Y.C. The optimal serum pepsinogen cut-off value for predicting histologically confirmed atrophic gastritis. Dig. Liver Dis. 2015, 47, 663-668. [CrossRef]

30. Myint, T.; Shiota, S.; Vilaichone, R.K.; Ni, N.; Aye, T.T.; Matsuda, M.; Tran, T.T.H.; Uchida, T.; Mahachai, V.; Yamaoka, Y. Prevalence of Helicobacter pylori infection and atrophic gastritis in patients with dyspeptic symptoms in Myanmar. World J. Gastroenterol. 2015, 21, 629-636. [CrossRef]

31. Kotachi, T.; Ito, M.; Yoshihara, M.; Boda, T.; Kiso, M.; Masuda, K.; Matsuo, T.; Tanaka, S.; Chayama, K. Serological Evaluation of Gastric Cancer Risk Based on Pepsinogen and Helicobacter pylori Antibody: Relationship to Endoscopic Findings. Digestion 2017, 95, 314-318. [CrossRef]

32. Leja, M.; Camargo, M.C.; Polaka, I.; Isajevs, S.; Liepniece-Karele, I.; Janciauskas, D.; Rudzite, D.; Kikuste, I.; Vanags, A.; Kojalo, I.; et al. Detection of gastric atrophy by circulating pepsinogens: A comparison of three assays. Helicobacter 2017, 22. [CrossRef]

33. Loong, T.H.; Soon, N.C.; Nik Mahmud, N.R.K.; Naidu, J.; Abdul Rani, R.; Abdul Hamid, N.; Hikmah Elias, M.; Rose, I.M.; Tamil, A.; Mokhtar, N.M.; et al. Serum pepsinogen and gastrin-17 as potential biomarkers for pre-malignant lesions in the gastric corpus. Biomed. Rep. 2017, 7, 460-468. [CrossRef] 
34. Chang, F.Y.; Lai, K.H.; Wang, T.F.; Lee, S.D.; Tsai, Y.T.; Tsay, S.H. Location and type of gastric carcinoma in relation to pepsinogen I level in blood. Scand. J. Gastroenterol. 1992, 27, 884-888. [CrossRef]

35. Hattori, Y.; Tashiro, H.; Kawamoto, T.; Kodama, Y. Sensitivity and specificity of mass screening for gastric cancer using the measurment of serum pepsinogens. Jpn. J. Cancer Res. 1995, 86, 1210-1215. [CrossRef]

36. Kodoi, A.; Yoshihara, M.; Sumii, K.; Haruma, K.; Kajiyama, G. Serum pepsinogen in screening for gastric cancer. J. Gastroenterol. 1995, 30, 452-460. [CrossRef]

37. Watanabe, Y.; Kurata, J.H.; Mizuno, S.; Mukai, M.; Inokuchi, H.; Miki, K.; Ozasa, K.; Kawai, K. Helicobacter pylori infection and gastric cancer: A nested case-control study in a rural area of Japan. Dig. Dis. Sci. 1997, 42, 1383-1387. [CrossRef]

38. Kitahara, F.; Kobayashi, K.; Sato, T.; Kojima, Y.; Araki, T.; Fujino, M.A. Accuracy of screening for gastric cancer using serum pepsinogen concentrations. Gut 1999, 44, 693-697. [CrossRef]

39. Ohata, H.; Kitauchi, S.; Yoshimura, N.; Mugitani, K.; Iwane, M.; Nakamura, H.; Yoshikawa, A.; Yanaoka, K.; Arii, K.; Tamai, H.; et al. Progression of chronic atrophic gastritis associated with Helicobacter pylori infection increases risk of gastric cancer. Int. J. Cancer 2004, 109, 138-143. [CrossRef]

40. Kim, J.R.; Lee, K.; Jung, W.T.; Lee, O.J.; Kim, T.H.; Kim, H.J.; Lee, J.S.; Passaro, D.J. Validity of serum pepsinogen levels and quininium resin test combined for gastric cancer screening. Cancer. Detect. Prev. 2005, 29, 570-575. [CrossRef]

41. Watabe, H.; Mitsushima, T.; Yamaji, Y.; Okamoto, M.; Wada, R.; Kokubo, T.; Doi, H.; Yoshida, H.; Kawabe, T.; Omata, M. Predicting the development of gastric cancer from combining Helicobacter pylori antibodies and serum pepsinogen status: A prospective endoscopic cohort study. Gut 2005, 54, 764-768. [CrossRef]

42. Oishi, Y.; Kiyohara, Y.; Kubo, M.; Tanaka, K.; Tanizaki, Y.; Ninomiya, T.; Doi, Y.; Shikata, K.; Yonemoto, K.; Shirota, T.; et al. The serum pepsinogen test as a predictor of gastric cancer: The Hisayama study. Am. J. Epidemiol. 2006, 163, 629-637. [CrossRef]

43. Sasazuki, S.; Inoue, M.; Iwasaki, M.; Otani, T.; Yamamoto, S.; Ikeda, S.; Hanaoka, T.; Tsugane, S. Effect of Helicobacter pylori infection combined with CagA and pepsinogen status on gastric cancer development among Japanese men and women: A nested case-control study. Cancer Epidemiol. Biomark. Prev. 2006, 15, 1341-1347. [CrossRef]

44. Sugiu, K.; Kamada, T.; Ito, M.; Kaya, S.; Tanaka, A.; Kusunoki, H.; Hata, J.; Haruma, K. Anti-parietal cell antibody and serum pepsinogen assessment in screening for gastric carcinoma. Dig. Liver Dis. 2006, 38, 303-307. [CrossRef]

45. Kang, J.M.; Kim, N.; Yoo, J.Y.; Park, Y.S.; Lee, D.H.; Kim, H.Y.; Lee, H.S.; Choe, G.; Kim, J.S.; Jung, H.C.; et al. The role of serum pepsinogen and gastrin test for the detection of gastric cancer in Korea. Helicobacter 2008, 13, 146-156. [CrossRef]

46. Yanaoka, K.; Oka, M.; Mukoubayashi, C.; Yoshimura, N.; Enomoto, S.; Iguchi, M.; Magari, H.; Utsunomiya, H.; Tamai, H.; Arii, K.; et al. Cancer high-risk subjects identified by serum pepsinogen tests: Outcomes after 10-year follow-up in asymptomatic middle-aged males. Cancer Epidemiol. Biomark. Prev. 2008, 17, 838-845. [CrossRef]

47. Yanaoka, K.; Oka, M.; Yoshimura, N.; Mukoubayashi, C.; Enomoto, S.; Iguchi, M.; Magari, H.; Utsunomiya, H.; Tamai, H.; Arii, K.; et al. Risk of gastric cancer in asymptomatic, middle-aged Japanese subjects based on serum pepsinogen and Helicobacter pylori antibody levels. Int. J. Cancer 2008, 123, 917-926. [CrossRef]

48. Miki, K.; Fujishiro, M.; Kodashima, S.; Yahagi, N. Long-term results of gastric cancer screening using the serum pepsinogen test method among an asymptomatic middle-aged Japanese population: Original article. Dig. Endosc. 2009, 21, 78-81. [CrossRef]

49. Mizuno, S.; Kobayashi, M.; Tomita, S.; Miki, I.; Masuda, A.; Onoyama, M.; Habu, Y.; Inokuchi, H.; Watanabe, Y. Validation of the pepsinogen test method for gastric cancer screening using a follow-up study. Gastric. Cancer 2009, 12, 158-163. [CrossRef]

50. Yamaji, Y.; Watabe, H.; Yoshida, H.; Kawabe, T.; Wada, R.; Mitsushima, T.; Omata, M. High-risk population for gastric cancer development based on serum pepsinogen status and lifestyle factors. Helicobacter 2009, 14, 81-86. [CrossRef]

51. Yanaoka, K.; Oka, M.; Ohata, H.; Yoshimura, N.; Deguchi, H.; Mukoubayashi, C.; Enomoto, S.; Inoue, I.; Iguchi, M.; Maekita, T.; et al. Eradication of Helicobacter pylori prevents cancer development in subjects with mild gastric atrophy identified by serum pepsinogen levels. Int. J. Cancer 2009, 125, 2697-2703. [CrossRef] 
52. Kwak, M.S.; Kim, N.; Lee, H.S.; Lee, H.E.; Jung, H.C.; Song, I.S. Predictive power of serum pepsinogen tests for the development of gastric cancer in comparison to the histologic risk index. Dig. Dis. Sci. 2010, 55, 2275-2282. [CrossRef] [PubMed]

53. Mizuno, S.; Miki, I.; Ishida, T.; Yoshida, M.; Onoyama, M.; Azuma, T.; Habu, Y.; Inokuchi, H.; Ozasa, K.; Miki, K.; et al. Prescreening of a high-risk group for gastric cancer by serologically determined Helicobacter pylori infection and atrophic gastritis. Dig. Dis. Sci. 2010, 55, 3132-3137. [CrossRef] [PubMed]

54. Aikou, S.; Ohmoto, Y.; Gunji, T.; Matsuhashi, N.; Ohtsu, H.; Miura, H.; Kubota, K.; Yamagata, Y.; Seto, Y.; Nakajima, A.; et al. Tests for serum levels of trefoil factor family proteins can improve gastric cancer screening. Gastroenterology 2011, 141, 837-845.e7. [CrossRef] [PubMed]

55. Chang, Y.W.; Hwangbo, Y.; Lee, J.W.; Jo, S.J.; Cho, J.H.; Shim, J.; Jang, J.Y.; Kim, H.J.; Kim, B.H. Clinical parameters including serum pepsinogen level and management strategy in patients with premalignant gastric dysplasia. Eur. J. Gastroenterol. Hepatol. 2011, 23, 405-410. [CrossRef] [PubMed]

56. Kaise, M.; Miwa, J.; Tashiro, J.; Ohmoto, Y.; Morimoto, S.; Kato, M.; Urashima, M.; Ikegami, M.; Tajiri, H. The combination of serum trefoil factor 3 and pepsinogen testing is a valid non-endoscopic biomarker for predicting the presence of gastric cancer: A new marker for gastric cancer risk. J. Gastroenterol. 2011, 46, 736-745. [CrossRef] [PubMed]

57. Kikuchi, R.; Abe, Y.; Iijima, K.; Koike, T.; Ara, N.; Uno, K.; Asanuma, K.; Asano, N.; Imatani, A.; Shimosegawa, T. Low serum levels of pepsinogen and gastrin 17 are predictive of extensive gastric atrophy with high-risk of early gastric cancer. Tohoku. J. Exp. Med. 2011, 223, 35-44. [CrossRef] [PubMed]

58. Ito, M.; Yoshihara, M.; Takata, S.; Wada, Y.; Matsuo, T.; Boda, T.; Tanaka, S.; Chayama, K. Serum screening for detection of high-risk group for early-stage diffuse type gastric cancer in Japanese. J. Gastroenterol. Hepatol. 2012, 27, 598-602. [CrossRef]

59. Lomba-Viana, R.; Dinis-Ribeiro, M.; Fonseca, F.; Vieira, A.S.; Bento, M.J.B.; Lomba-Viana, H. Serum pepsinogen test for early detection of gastric cancer in a European Country. Eur. J. Gastroenterol. Hepatol. 2012, 24, 37-41. [CrossRef]

60. Zhang, X.; Xue, L.; Xing, L.; Wang, J.; Cui, J.; Mi, J.; Xing, X.; Wang, J.; Du, Z.; Misumi, J.; et al. Low serum pepsinogen $\mathrm{i}$ and pepsinogen I/II ratio and Helicobacter pylori infection are associated with increased risk of gastric cancer: 14-year follow up result in a rural Chinese community. Int. J. Cancer 2012, 130, 1614-1619. [CrossRef]

61. Choi, H.S.; Lee, S.Y.; Kim, J.H.; Sung, I.K.; Park, H.S.; Shim, C.S.; Jin, C.J. Combining the serum pepsinogen level and Helicobacter pylori antibody test for predicting the histology of gastric neoplasm. J. Dig. Dis. 2014, 15, 293-298. [CrossRef]

62. Huang, Z.; Zhang, X.; Lu, H.; Wu, L.; Wang, D.; Zhang, Q.; Ding, H. Serum trefoil factor 3 is a promising non-invasive biomarker for gastric cancer screening: A monocentric cohort study in China. BMC Gastroenterol. 2014, 14, 74. [CrossRef]

63. Yoshida, T.; Kato, J.; Inoue, I.; Yoshimura, N.; Deguchi, H.; Mukoubayashi, C.; Oka, M.; Watanabe, M.; Enomoto, S.; Niwa, T.; et al. Cancer development based on chronic active gastritis and resulting gastric atrophy as assessed by serum levels of pepsinogen and Helicobacter pylori antibody titer. Int. J. Cancer 2014, 134, 1445-1457. [CrossRef]

64. Zhang, X.M.; Li, J.X.; Zhang, G.Y.; Li, X.H.; Gu, H. The value of serum pepsinogen levels for the diagnosis of gastric diseases in Chinese Han people in midsouth China. BMC Gastroenterol. 2014, 14, 3. [CrossRef]

65. Eybpoosh, S.; Talebkhan, Y.; Saberi, S.; Esmaeili, M.; Oghalaie, A.; Ebrahimzadeh, F.; Karimi, T.; Abdirad, A.; Nahvijou, A.; Mohagheghi, M.A.; et al. Age-specific gastric cancer risk indicated by the combination of Helicobacter pylori sero-status and serum pepsinogen levels. Iran. Biomed. J. 2015, 19, 133-142.

66. Ikeda, F.; Shikata, K.; Hata, J.; Fukuhara, M.; Hirakawa, Y.; Ohara, T.; Mukai, N.; Nagata, M.; Yoshida, D.; Yonemoto, K.; et al. Combination of Helicobacter pylori Antibody and Serum Pepsinogen as a Good Predictive Tool of Gastric Cancer Incidence: 20-Year Prospective Data From the Hisayama Study. J. Epidemiol. 2016, 26, 629-636. [CrossRef]

67. Cho, J.H.; Jeon, S.R.; Kim, H.G.; Jin, S.Y.; Park, S. The serum pepsinogen levels for risk assessment of gastric neoplasms: New proposal from a case-control study in Korea. Medicine 2017, 96, e7603. [CrossRef]

68. Hamashima, C.; Sasazuki, S.; Inoue, M.; Tsugane, S. Receiver operating characteristic analysis of prediction for gastric cancer development using serum pepsinogen and Helicobacter pylori antibody tests. BMC Cancer 2017, 17, 183. [CrossRef] 
69. Tu, H.; Sun, L.; Dong, X.; Gong, Y.; Xu, Q.; Jing, J.; Bostick, R.M.; Wu, X.; Yuan, Y. A Serological Biopsy Using Five Stomach-Specific Circulating Biomarkers for Gastric Cancer Risk Assessment: A Multi-Phase Study. Am. J. Gastroenterol. 2017, 112, 704-715. [CrossRef]

70. Castro, C.; Dinis-Ribeiro, M.; Rodrigues, A.N.G.; Calheiros, T.; Santos, J.; Pereira, P.; Ramos, M.; Cunha, H.; Andrade, M.; Costa, A.; et al. Western long-term accuracy of serum pepsinogen-based gastric cancer screening. Eur. J. Gastroenterol. Hepatol. 2018, 30, 274-277. [CrossRef]

71. Kwak, M.S.; Chung, G.E.; Chung, S.J.; Kang, S.J.; Yang, J.I.; Kim, J.S. Predicting the development of gastric neoplasms in a healthcare cohort by combining Helicobacter pylori antibodies and serum pepsinogen: A 5-year longitudinal study. Gastroenterol. Res. Pract. 2018, 2018, 8796165. [CrossRef]

72. Lee, H.S.; Jeon, S.W.; Nomura, S.; Seto, Y.; Kwon, Y.H.; Nam, S.Y.; Ishibashi, Y.; Ohtsu, H.; Ohmoto, Y.; Yang, H.M. Screening biomarker as an alternative to endoscopy for the detection of early gastric cancer: The combination of serum trefoil factor family 3 and pepsinogen. Gastroenterol. Res. Pract. 2018, 2018, 1024074. [CrossRef]

73. Sjomina, O.; Pavlova, J.; Daugule, I.; Janovic, P.; Kikuste, I.; Vanags, A.; Tolmanis, I.; Rudzite, D.; Polaka, I.; Kojalo, I.; et al. Pepsinogen test for the evaluation of precancerous changes in gastric mucosa: A population-based study. J. Gastrointestin. Liver Dis. 2018, 27, 11-17.

74. Cha, J.H.; Jang, J.S. Clinical correlation between serum pepsinogen level and gastric atrophy in gastric neoplasm. Korean. J. Intern. Med. 2018. [CrossRef]

75. Lee, S.Y. Endoscopic gastritis, serum pepsinogen assay, and Helicobacter pylori infection. Korean J. Intern. Med. 2016, 31, 835-844. [CrossRef]

76. Yeh, J.M.; Hur, C.; Ward, Z.; Schrag, D.; Goldie, S.J. Gastric adenocarcinoma screening and prevention in the era of new biomarker and endoscopic technologies: A cost-effectiveness analysis. Gut 2016, 65, 563-574. [CrossRef]

77. Mukoubayashi, C.; Yanaoka, K.; Ohata, H.; Arii, K.; Tamai, H.; Oka, M.; Ichinose, M. Serum pepsinogen and gastric cancer screening. Intern. Med. 2007, 46, 261-266. [CrossRef]

78. De Re, V.; Orzes, E.; Canzonieri, V.; Maiero, S.; Fornasarig, M.; Alessandrini, L.; Cervo, S.; Steffan, A.; Zanette, G.; Mazzon, C.; et al. Pepsinogens to distinguish patients with gastric intestinal metaplasia and Helicobacter pylori infection among populations at risk for gastric cancer. Clin. Transl. Gastroenterol. 2016, 7, e183. [CrossRef]

79. Kim, N.; Jung, H.C. The role of serum pepsinogen in the detection of gastric cancer. Gut Liver 2010, 4, 307-319. [CrossRef] 